\title{
Comparison of measured brightness temperatures from SMOS with modelled ones from ORCHIDEE and H-TESSEL over the Iberian Peninsula
}

\author{
Anaïs Barella-Ortiz ${ }^{1,5}$, Jan Polcher ${ }^{1,5}$, Patricia de Rosnay ${ }^{2}$, Maria Piles ${ }^{3, a}$, and Emiliano Gelati ${ }^{4,5}$ \\ ${ }^{1}$ Laboratoire de Météorologie Dynamique du CNRS, IPSL, École Polytechnique, Université Paris-Saclay, France \\ ${ }^{2}$ European Centre for Medium-Range Weather Forecasts, Reading, UK \\ ${ }^{3}$ Barcelona Expert Center, Institute of Marine Sciences, CSIC, Pg. Marítim de la Barceloneta 37-49, 08003 Barcelona, Spain \\ ${ }^{4}$ CNRM-GAME (Météo-France, CNRS), Toulouse, France \\ ${ }^{5}$ Centre National de la Recherche Scientifique (CNRS) \\ ${ }^{a}$ currently at: Image Processing Lab (IPL), Universitat de València, C/Catedrático José Beltran 2, 46980 Valencia, Spain
}

Correspondence to: Anaïs Barella-Ortiz (anais.barella-ortiz@lmd.jussieu.fr)

Received: 3 September 2015 - Published in Hydrol. Earth Syst. Sci. Discuss.: 15 December 2015

Revised: 25 November 2016 - Accepted: 29 November 2016 - Published: 23 January 2017

\begin{abstract}
L-band radiometry is considered to be one of the most suitable techniques to estimate surface soil moisture (SSM) by means of remote sensing. Brightness temperatures are key in this process, as they are the main input in the retrieval algorithm which yields SSM estimates. The work exposed compares brightness temperatures measured by the SMOS mission to two different sets of modelled ones, over the Iberian Peninsula from 2010 to 2012. The two modelled sets were estimated using a radiative transfer model and state variables from two land-surface models: (i) ORCHIDEE and (ii) H-TESSEL. The radiative transfer model used is the CMEM.

Measured and modelled brightness temperatures show a good agreement in their temporal evolution, but their spatial structures are not consistent. An empirical orthogonal function analysis of the brightness temperature's error identifies a dominant structure over the south-west of the Iberian Peninsula which evolves during the year and is maximum in autumn and winter. Hypotheses concerning forcing-induced biases and assumptions made in the radiative transfer model are analysed to explain this inconsistency, but no candidate is found to be responsible for the weak spatial correlations at the moment. Further hypotheses are proposed and will be explored in a forthcoming paper. The analysis of spatial inconsistencies between modelled and measured TBs is important, as these can affect the estimation of geophysical variables
\end{abstract}

and TB assimilation in operational models, as well as result in misleading validation studies.

\section{Introduction}

The United Nations (UN), the Food and Agriculture Organization (FAO), and the World Health Organization (WHO) have reported that water resources are not being managed in an optimum way at present. As a result, scarcity, hygiene, and pollution issues related to improper water policies have been detected. In addition, the world's population is expected to grow by 2 to 3 billion people over the next 40 years according to the UN's World Water Development Report from 2012 (WWAP, 2012). This will lead to a significant increase in freshwater demand which will likely be affected by the effect of a changing climate.

To achieve a better management of water resources, it is necessary to improve our understanding of hydrological processes. In order to do this, the study of soil moisture (SM) is essential. It is defined as the water content in the soil and has a key role in the soil-atmosphere interface. SM determines whether evaporation over land surfaces occurs at a potential rate (controlled by atmospheric conditions) or whether it is limited by the available moisture (Milly, 1992). In addition, it influences several processes, like infiltration and surface 
temperature, which have an important effect on plant growth and the general state of the continental surfaces. However, $\mathrm{SM}$ is a complex variable to model as the interactions between soils and water are not simple to represent. Its definition requires knowledge of soil hydraulic conductivity, which is not often available as direct measurements. These are used to access the saturated and residual soil water content, as well as for SM dynamics. Pedo-transfer functions (Marthews et al., 2014) allow us to estimate hydrodynamic characteristics of the soil from available soil texture and structure information. However, the suitability of these functions is under debate (Baroni et al., 2008), as their performance depends on several factors like the climate, geology, and the measurement techniques used. Furthermore, different hydrological schemes are found in land-surface models (LSMs), leading to various ways of understanding and formulating soil moisture.

Remotely sensed soil moisture products have brought about new ways to perform data retrieval, adding new observations to data assimilation chains. The optimal combination of these products with modelled ones is expected to provide better estimates of the true soil moisture state. Remote sensing allows us to estimate SM by means of retrieval algorithms, like inversion algorithms (Kerr et al., 2012) or neural networks (Kolassa et al., 2013). Their main input depends on the type of sensor used. This is backscattering for an active sensor and brightness temperature (TB) for a passive sensor. TB corresponds to the radiance emitted by the Earth at a given wavelength and is the magnitude measured by a radiometer. It is defined as the physical temperature times the emissivity of the surface.

L-band radiometry is one of the best methods to estimate soil moisture, due to the relation between SM and the soil dielectric constant $(\epsilon)$ in this wavelength. The latter differs significantly between a dry soil and water (4 vs. 80 , respectively) and this difference is key to estimating the soil water content. It should be noted that the retrieved SM corresponds to the water contained in the first centimetres of the soil. The penetration depth in averaged conditions is about $5 \mathrm{~cm}$ (Kerr et al., 2010). Therefore, we will refer to surface soil moisture (SSM) instead of soil moisture. Some studies, like Escorihuela et al. (2010), lower the penetration depth to $1-2 \mathrm{~cm}$.

In the last decade, three space missions have been launched with L-band radiometers on-board: the Soil Moisture and Ocean Salinity (SMOS) mission (Kerr et al., 2010), the Aquarius/SAC-D mission (Le Vine et al., 2010), and the Soil Moisture Active and Passive (SMAP) mission (Entekhabi et al., 2010).

A large number of validation studies of remotely sensed SSM products have been carried out (Albergel et al., 2011; Sánchez et al., 2012; Bircher et al., 2013). These studies are usually performed using airborne and/or ground-observed data over a well-equipped site. Other studies, like the one described in González-Zamora et al. (2015), validate SMOS SSM products using in situ soil moisture measurement net- works, which allow one to extend the study period to annual and inter-annual scales. Several studies have been performed to validate brightness temperatures too (Rüdiger et al., 2011; Montzka et al., 2013). In Bircher et al. (2013) TBs are also validated with network and airborne data over a SMOS pixel in the Skjern River catchment (Denmark). LSMs coupled to radiative transfer models (RTMs) can contribute to the analysis and validation of passive microwave (MW) data. Models permit extension of the validation to a longer period of time and perform an extensive analysis of observed and retrieved data, as shown in Schlenz et al. (2012). In this study, they compare TBs and vegetation optical depth from SMOS with modelled ones obtained from a LSM coupled to a radiative transfer model, over a period of 7 months in 2011 at the Vils test site (Germany). Comparing modelled with satellitemeasured brightness temperatures can help to better understand inconsistencies between retrieved and modelled data. It provides information regarding the origin of their differences and whether they are due to the retrieval algorithm or to issues related to the modelling process.

Polcher et al. (2016) present the first comparison of the spatial patterns of the Level 2 (L2) SMOS product corresponding to retrieved SSM, with SSM modelled by the ORganising Carbon and Hydrology In Dynamic EcosystEms (ORCHIDEE) LSM (de Rosnay and Polcher, 1998; Krinner et al., 2005) over the Iberian Peninsula (IP) from 2010 to 2013. They identify inconsistencies between the spatial structures of retrieved and modelled SSM. The main objective of the work presented herein is to extend the analysis of this inconsistency by comparing brightness temperatures measured by SMOS (Level 1C, L1C, product) with modelled ones obtained from the coupling of ORCHIDEE's state variables and a RTM. In addition, a second set of modelled TBs using state variables from the Hydrology Tiled ECMWF Scheme for Surface Exchanges over Land (H-TESSEL) is included in the comparison. The RTM used is the Community Microwave Emission Model (CMEM) (de Rosnay et al., 2009), developed by the European Centre for MediumRange Weather Forecasts (ECMWF). The comparison is performed over the same period and region as the study carried out by Polcher et al. (2016). The IP is an excellent test case for remote sensing of SSM, as its two characteristic climate regimes (oceanic and Mediterranean) result in a strong contrast in soil water content. Furthermore, SSM is a critical variable regarding water resources, especially in the IP, which makes this study even more necessary.

The data from SMOS and the LSMs used in this paper will be presented in the next section. A methodology section follows describing the data filtering and sampling processes carried out, together with the analysis performed to compare TBs. Afterwards, results will be presented. First, modelled and measured TBs will be compared. Second, their difference will be characterized spatially and temporally and certain hypotheses to explain the differences found in the TB comparison will be analysed. Third, we will study the am- 
plitude of the annual cycle of the TB signals. The paper will end with discussion and conclusion sections.

\section{Data}

\subsection{SMOS retrievals of TB}

The SMOS mission is the second Earth Explorer Opportunity mission from the European Space Agency (ESA). The SMOS satellite was launched on 2 November 2009. One of its main objectives is to provide surface soil moisture over land with a target accuracy of $0.04 \mathrm{~m}^{3} \mathrm{~m}^{-3}$.

TBs are the main input of SMOS's soil moisture retrieval algorithm. L-band brightness temperatures are measured by the SMOS radiometer at different incidence angles (from 0 to $65^{\circ}$ ) and polarizations $(\mathrm{H}, \mathrm{V}, \mathrm{HV})$. The retrieval algorithm also models TBs using the state-of-the-art L-band Microwave Emission of the Biosphere (L-MEB) forward model (Wigneron et al., 2007) with some modifications. These brightness temperatures are then used to retrieve SSM using an inversion algorithm based on an iterative approach. Its objective is to minimize the sum of the squared weighted differences between measured and modelled TBs for all available incidence angles. Details about the retrieval algorithm are provided in Kerr et al. (2012).

The L1C product containing horizontally and vertically polarized brightness temperatures was provided by the SMOS Barcelona Expert Center. From now on, this product will be referred to as $\mathrm{TB}_{\mathrm{SM}}$.

The SMOS L1C v5.05 product over the $10^{\circ} \mathrm{W}: 5^{\circ} \mathrm{W}$ to $45^{\circ} \mathrm{N}: 35^{\circ} \mathrm{N}$ region was selected and SMOS TBs at the antenna reference plane were derived: TBs were first screened out for radio-frequency interferences (RFIs) (strong, point source, and tails), and also for Sun (glint area, aliases, and tails) and Moon (aliases) contamination, using the corresponding flags. Ionospheric effects (geometric and Faraday rotations) were later corrected to obtain $\mathrm{TB}$ at the top of the atmosphere (TOA). TB maps at a constant incidence angle of $42.5 \pm 5^{\circ}$ were obtained through chi-squared linear fit of all values included in the interval $42.5 \pm 5^{\circ}$, which is the methodology used to generate the SMOS L1C browse product (McMullan et al., 2008). Finally, these maps were resampled from the Icosahedral Snyder Equal Area (ISEA) 4H9 grid to a $0.25^{\circ}$ regular latitude-longitude grid, to facilitate its manipulation.

\subsection{Modelled TB: CMEM}

The Community Microwave Emission Modelling (CMEM) platform (de Rosnay et al., 2009), developed at ECMWF, is a forward operator for low-frequency passive MW brightness temperatures of the surface. Its physics is based on that of the L-MEB forward model and the Land Surface Microwave Emission Model (LSMEM) (Drusch et al., 2001). CMEM is characterized by its modular structure, which allows the user to choose among different physical configurations to compute TB's key parameters. Polarized brightness temperatures provided at TOA result from the contribution of three dielectric layers: atmosphere, soil, and vegetation. Snow, also considered, is characterized as a single additional homogeneous layer.

The two sets of modelled TBs used in this study were estimated by means of the CMEM provided with state variables from (i) ORCHIDEE, and (ii) H-TESSEL simulations. From now on we will refer to these sets as $\mathrm{TB}_{\mathrm{OR}}$ and $\mathrm{TB}_{\mathrm{HT}}$, respectively. $\mathrm{TB}_{\mathrm{OR}}$ was computed specifically for this study, while $\mathrm{TB}_{\mathrm{HT}}$ was provided by the ECMWF to widen the comparison between measured and modelled data. The CMEM configuration used to compute each set of TB is listed in Table 1. The table is divided into three configuration categories: physical, observing, and soil and atmospheric levels. Even though both sets have similar configurations, there are some differences which are explained below.

First, the "Physical configuration" of $\mathrm{TB}_{\mathrm{OR}}$ was selected to be as similar as possible to $\mathrm{TB}_{\mathrm{HT}}$. However, they differ in the parameterization used to compute the smooth surface emissivity $\left(\varepsilon_{\mathrm{s}}\right)$. For $\mathrm{TB}_{\mathrm{HT}}$ the reflectivity of the flat soil surface was computed following the Fresnel law (Ulaby et al., 1986), so it is expressed as a function of the soil dielectric constant and the observation incidence angle. This formulation considers the emission at the soil interface. As it is simple and affordable in computing time, it is commonly used for microwave emission modelling and soil moisture retrieval, as well as for operational applications (e.g. Wigneron et al., 2007; de Rosnay et al., 2009). It assumes an a priori soil moisture sampling depth, which in this study corresponds to the first soil layer of the land-surface model $(7 \mathrm{~cm}$ for $\mathrm{H}$-TESSEL). For $\mathrm{TB}_{\mathrm{OR}}$, the multilayered soil hydrology of ORCHIDEE allows us to take into account the soil moisture profile and the resulting volume scattering effects on the soil emission. Therefore the reflectivity of the flat soil surface was computed using the parameterization proposed by Wilheit (1978). The different parameterizations chosen to calculate $\varepsilon_{\mathrm{s}}$ lead to another variation between the CMEM configurations. If $\varepsilon_{\mathrm{S}}$ is computed using Wilheit (1978), the soil temperature profile is used to compute the effective temperature $\left(T_{\text {eff }}\right)$. By contrast, if the Fresnel law is used, the user can choose between different parameterizations to compute $T_{\text {eff. For }} \mathrm{TB}_{\mathrm{HT}}$, Wigneron et al. (2001) was selected.

Second, the "Observing configuration" considers different incidence angles for each set. Although the available $\mathrm{TB}_{\mathrm{HT}}$ were modelled considering an angle of $40^{\circ}, 42.5^{\circ}$ was used to model $\mathrm{TB}_{\mathrm{OR}}$, because measured $\mathrm{TBs}$ were provided at this angle.

Third, a different number of soil layers was defined for the "Soil and atmospheric level configuration": 11 (TB $\left.{ }_{\mathrm{OR}}\right)$ and $3\left(\mathrm{~TB}_{\mathrm{HT}}\right)$. ORCHIDEE's soil discretization is finer. For instance, its first layer's depth is of the order of millimetres, while H-TESSEL's is of centimetres. In order to evaluate the role of these differences in the vertical discretization and the 
Table 1. CMEM configuration for the two sets of modelled TBs.

\begin{tabular}{llrc}
\hline & Configuration & Parameterization \\
\cline { 3 - 4 } & & ORCHIDEE & H-TESSEL \\
\hline Physical configuration & Soil dielectric constant & Wang and Schmugge (1980) \\
& Effective temperature & Soil temperature profile & Wigneron et al. (2001) \\
& Smooth surface emissivity & Wresnel law \\
& Rough surface emissivity & Wigneron et al. (2001) \\
& Vegetation optical depth & Wigneron et al. (2007) \\
& Atmospheric optical depth & Pellarin et al. (2003) \\
& Temperature of vegetation & Surface soil temperature \\
& Vegetation cover input data & Ecoclimap \\
\hline Observing configuration & Microwave frequency & $1.4 \mathrm{Ghz}$ \\
& Incidence angle & $40^{\circ}$ \\
\hline Soil and atmospheric level configuration & Number of soil layers* & 11 & 3 \\
& Number of layers in the top $5 \mathrm{~cm}$ & 5 & 1 \\
\hline
\end{tabular}

Layer depths of the hydrological schemes in cm: ORCHIDEE $=0.099,0.391,0.978,2.151,4.497,9.189,18.570,37.340,74.880,150$, and 200; H-TESSEL $=7,21,72$, and 189. * Layer depths of H-TESSEL's hydrological scheme (cm): 7, 21, 72, and 189.

LSMs, we performed the sensitivity analysis detailed in the next paragraph.

In addition to the CMEM simulations performed to model $\mathrm{TB}_{\mathrm{OR}}$ and $\mathrm{TB}_{\mathrm{HT}}$ using the configurations indicated in Table 1 , the following simulations were carried out to test whether parameterization assumptions could affect the resulting TBs.

- Simulation 1: $\mathrm{TB}_{\mathrm{HT}(\mathrm{VC})}$, where the subscript "VC" stands for "vegetation cover".

Vegetation cover is a key input. Since this parameter is directly related to land-surface emissivity, the effects of a different vegetation cover were tested on $\mathrm{TB}_{\mathrm{HT}}$. For this matter, a new set of TBs was modelled using H-TESSEL's state variables with the same configuration as detailed in Table 1, except for the vegetation cover input, where H-TESSEL's prescribed vegetation (Boussetta et al., 2013) was considered. One of the differences between this input and the ECOCLIMAP database (used in the original configuration) is that the former consists of 20 vegetation types, while the latter considers 7.

- Simulation 2: $\mathrm{TB}_{\mathrm{OR}(\mathrm{SD})}$, where the subscript "SD" stands for "soil discretization".

The impact of a coarser soil representation on modelled TBs was tested by recomputing $\mathrm{TB}_{\mathrm{OR}}$ using $\mathrm{OR}$ CHIDEE's state variables averaged to 3 soil layers: upper $(9 \mathrm{~cm})$, medium $(66 \mathrm{~cm})$, and lower $(125 \mathrm{~cm})$.

- Simulation 3: $\mathrm{TB}_{\mathrm{OR}(\mathrm{FW})}$, where the subscript "FW" stands for "Fresnel Wigneron".

We tested the combined effect of using the Fresnel law to compute $\varepsilon_{\mathrm{s}}$, rather than the parameterization proposed by Wilheit (1978), and calculating $T_{\text {eff }}$ using the
Table 2. Input variables for the CMEM to compute TBs at TOA.

\begin{tabular}{lll}
\hline Soil conditions & Constant fields & $\begin{array}{l}\text { Soil texture fraction }(\%) \\
\text { Orography }(\mathrm{km})\end{array}$ \\
\hline Vegetation & Constant fields & $\begin{array}{l}\text { High and low vegetation types } \\
\text { High and low vegetation fractions } \\
\end{array}$ \\
& Water fraction \\
& Dynamic fields & Low vegetation LAI \\
\hline Meteorology & Dynamic fields & Soil moisture profile $\left(\mathrm{m}^{3} \mathrm{~m}^{-3}\right)$ \\
& & Soil temperature profile $(\mathrm{K})$ \\
& & Skin temperature $(\mathrm{K})$ \\
& & Snow depth $(\mathrm{m})$ \\
& & Snow density $\left(\mathrm{kg} \mathrm{m} \mathrm{m}^{-3}\right)$ \\
& & $2 \mathrm{~m}$ temperature $(\mathrm{K})$ \\
\hline
\end{tabular}

methodology proposed by Wigneron (2001) instead of the soil temperature profile. For this, TBs were simulated using ORCHIDEE's state variables.

The input variables required by the CMEM to model TBs are summarized in Table 2. They are classified into dynamic and constant fields and consist of meteorological data, vegetation characteristics, and soil conditions.

\subsubsection{The ORCHIDEE and H-TESSEL land-surface models}

\section{ORCHIDEE}

The ORCHIDEE LSM (de Rosnay and Polcher, 1998; Krinner et al., 2005) was developed by the Institut Pierre-Simon Laplace (IPSL). It can be run coupled with the LMDZ general circulation model, which was developed by the Laboratoire de Météorologie Dynamique (LMD), or in stand-alone mode. Uncoupled simulations were carried out for this study. 
The hydrological scheme used by ORCHIDEE approaches hydrology through the resolution of a diffusive equation with a multilayered scheme. For this, the Fokker-Planck equation is solved over a soil $2 \mathrm{~m}$ deep with an 11-layer discretization. The layers' depths are shown in Table 1. The lower boundary condition is free drainage, under the hypothesis that the water content gradient between the last modelled layer and the next one (not modelled) is zero. The upper boundary condition sets the bare soil evaporation as the maximum upward hydrological flux which is permitted by diffusion if it is lower than potential evaporation.

The multilayer scheme considers a sub-grid variability of soil moisture, which together with the fine soil discretization improves the representation of infiltration processes. The soil infiltration follows the Green-Ampt equation (Green and Ampt, 1911) to represent the evolution in time of the wetting front through the soil layers. It should be noted that partial re-infiltration occurs from surface runoff if the local slope of the grid cell is $\leq 0.5 \%$ (D'Orgeval et al., 2008). Each grid box has a unique soil texture and structure (Post and Zobler, 2000), but three different soil columns are considered, each one with its own soil moisture discretization and root profile. These are classified as bare soil and low and high vegetation, regrouping the 13 plant functional types (PFT) defined in ORCHIDEE. These PFTs contribute to the soil layers of each grouping of a root density to compute extraction and soil moisture stress to the plants. The water balance is solved for each soil column, resulting in three different soil moisture profiles in each grid box.

ORCHIDEE's soil temperature profile is calculated by solving the heat diffusion equation. In contrast to the hydrological scheme, it considers a seven-layer discretization, where the layers' thicknesses follow a geometric series of ratio 2, and a total soil depth of $5.5 \mathrm{~m}$ (Hourdin, 1992; Wang et al., 2016). For this study, the first $2 \mathrm{~m}$ of the temperature profile were calculated following the same soil discretization as the one considered in the soil moisture calculation. The energy balance takes into account the skin temperature as presented in Schulz et al. (2001) to derive the land-surface temperature (LST). The soil and vegetation are considered as a single medium assigned with a surface temperature (Santaren et al., 2007).

\section{H-TESSEL}

The H-TESSEL LSM (Balsamo et al., 2009), developed by the ECMWF, revises and improves certain aspects regarding the soil hydrology of the TESSEL model. Its hydrology scheme solves a diffusive equation over a multilayer scheme with a four-layer discretization. Layer depths follow an approximate geometric relation (Table 1). In addition, the soil can be covered by a single snow layer. H-TESSEL considers the same lower boundary condition as ORCHIDEE. However, it differs in the upper one that also accounts for infiltration. It defines a maximum infiltration rate given by the maximum downward diffusion from the saturated surface. Once this rate is exceeded by the water flux at the surface, the excess of water is derived to surface runoff.

The model considers six types of tiles over land: bare soil, low and high vegetation, water intercepted by leaves, as well as shaded and exposed snow. Each one of these has its own energy and water balance. However, only one soil moisture reservoir is considered. Recent improvements have replaced a globally uniform soil type (loamy) with a spatially varying one (coarse, medium, medium-fine, fine, very fine, organic). Surface runoff, based on variable infiltration capacity, was also a recent improvement.

H-TESSEL's soil temperature profile is computed using the same soil discretization as the one defined in its hydrological scheme. The soil heat budget follows a Fourier diffusion law, which has been modified to also consider thermal effects caused by changes in the soil water phases (Holmes et al., 2012). To simulate the LST, a skin layer is defined representing (i) the layer of vegetation, (ii) the top layer of bare soil, or (iii) the top layer of the snowpack. The surface energy balance equation is then linearized for each tile (Viterbo and Beljaars, 1995).

Both LSMs are forced with the ERA-Interim forcing (Dee et al. 2011), which is suitable for this study because it ranges from 1979 to 2012 and recent data were needed to perform the comparison with SMOSs. We are aware that biases in this type of forcing have an effect on the LSM simulations (Ngo-Duc et al., 2005). ORCHIDEE was configured to output hourly TB values. However, $\mathrm{TB}_{\mathrm{HT}}$ is only available at 6hourly time steps (at 00:00, 06:00, 12:00, and 18:00 h). Due to this difference, each set of modelled TBs was sampled in a different way to approximate $\mathrm{TB}_{\mathrm{SM}}$ measurement times. The sampling processes will be explained in Sect. 3 .

The above paragraphs show that the hydrology, soil processes, and land-surface temperatures are approached very differently by both models. Therefore, the impact of these differences needs to be considered when comparing simulated TBs.

\subsection{Precipitation and land-surface temperature}

One important common feature of the presented model simulations is the forcing data. Since biases in the imposed atmospheric conditions can affect modelled TBs, it was decided to validate two important variables for which independent observations exist. Focus was placed on precipitation $(P)$ and the LST, as they are key variables for the water and radiative balances.

$P$ is the main driver of SSM, and this directly drives the L-band emissivity. According to Zollina et al. (2004), $P$ generated by a reanalysis (like ERA-Interim which is used here) is highly model-dependent, and it should be noted that models do not represent accurately all the physical processes of the atmospheric water cycle. Therefore, the verification of 
this forcing variable of the LSMs with independent data is essential.

As for the radiative balance, the available energy at the surface is one of the major drivers of LST. We chose to verify this variable in this study for two reasons. First, it provides a good summary of the surface energy balance. Second, it is a key parameter in CMEM's estimation of TB. Therefore, its analysis will indicate whether the LSM thermodynamics shows biases with spatio-temporal characteristics similar to those from TBs.

The independent datasets used for validation are

- $P$ from the E-OBS dataset (Haylock et al., 2008), and

- LST provided by the LandSAF product (http://landsaf. meteo.pt).

It should be noted that these products have errors which must be taken into account when used. For example, E-OBS data can be over-smoothed depending on the station network density (Hofstra et al., 2010), or for LST sensor noise, emissivity uncertainties, etc., are error sources which can propagate in the LandSAf algorithm (Freitas et al., 2007). However, these products are accepted by the community as being representative of large spatial scales and we have selected them as the reference to benchmark $P$ and LST.

\section{Methods}

\subsection{Data sampling and filtering processes}

To compare modelled and measured brightness temperatures, $\mathrm{TB}_{\mathrm{OR}}$ and $\mathrm{TB}_{\mathrm{HT}}$ were sampled with $\mathrm{TB}_{\mathrm{SM}}$ and remapped to the nearest neighbour of the SMOS grid. This allows one to keep the spatial structures of the coarse model resolution. Next, the three TB signals were filtered to exclude certain situations, such as frozen soils or RFIs, which are known to make SSM estimates unreliable.

\subsubsection{Sampling}

The objective of sampling the data is to use only modelled TBs corresponding to available measured values. $\mathrm{TB}_{\mathrm{OR}}$ were sampled at an hourly scale. However, $\mathrm{TB}_{\mathrm{HT}}$ consists of 6hourly values, thus potentially resulting in a large number of neglected data because $\mathrm{TB}_{\mathrm{HT}}$ and SMOS time steps did not always correspond. Therefore, $\mathrm{TB}_{\mathrm{HT}}$ were sampled considering a $3 \mathrm{~h}$ window around the observation in order to keep a larger number of modelled data for the comparison. To test the impact of this approximation, we also applied it to the $\mathrm{TB}_{\mathrm{OR}}$ and compared it to the original hourly data. Differences between them were under $0.1 \%$ for the diagnostics used here, and, thus, it was considered to be negligible.

\subsubsection{Filtering}

Data were filtered to discard unreasonable TB values from the comparison study. Filtering rules were devised following the ECMWF criteria used to screen $\mathrm{TB}_{\mathrm{HT}}$ (Table 3). Common filters were also applied to measured and modelled TBs.

The filters applied in $\mathrm{TB}_{\mathrm{HT}}$ corresponding to the water content in snow cover (snow water equivalent) and the criterion on ERA-Interim's $2 \mathrm{~m}$ air temperature aim to discard frozen soils, which might affect the SM retrieval (Dente et al., 2012). The same result was achieved by filtering $\mathrm{TB}_{\mathrm{OR}}$ with the $2 \mathrm{~m}$ temperature from the forcing (as in the previous case) as well as with ORCHIDEE's average surface temperature. The first common criterion excludes TBs higher than $300 \mathrm{~K}$ to avoid effects of RFIs, which can result in overestimated brightness temperatures (can be higher than $1000 \mathrm{~K}$ ). The second common criterion aims at removing points which might be influenced by coastal or topographic effects, as does H-TESSEL's orography (slope) criterion. The mask was built using the L2 SMOS product. Any pixel with no surface soil moisture data retrieved was excluded from the comparison. The surrounding 24 pixels were also excluded to avoid effects of abrupt changes in land-sea transitions. In the end, only data which are not masked in either case are retained.

\subsection{Comparison analyses}

\subsubsection{Spatio-temporal correlation}

The first diagnostic performed to compare measured and modelled TBs consisted in temporal and spatial correlation analyses. Our aim was to study the similarity between the spatio-temporal patterns. We used the Pearson productmoment correlation coefficient. Only values statistically significant at the $95 \%$ level were considered. An averaging window of 5 days was applied to the data before performing spatial correlation analysis to ensure the highest coverage possible.

Even though the correlation coefficient is a widely used statistical tool, it may not be suitable when analysing certain fields. For instance, Polcher et al. (2016) show that temporal correlation measured between remotely sensed, in situ, and modelled SSM is mainly driven by the high-frequency behaviour of SSM. Therefore, this diagnostic is not very sensitive to the slower variations of the field studied. Performing the correlation analyses allowed us to study whether this conclusion also applies to TBs.

\subsubsection{Empirical orthogonal function}

The empirical orthogonal function (EOF) analysis extracts the dominant spatial and temporal modes of variability of a field $(F)$. It relates the spatial patterns of each variation mode to a time series and its explained variance. 
Table 3. TB filtering criteria to keep data, applied to the TB signals.

\begin{tabular}{lll}
\hline TB & TBR $_{\mathrm{HT}}$ & All TB signals \\
\hline $\begin{array}{l}\text { ORCHIDEE's daily average surface } \\
\text { temperature }>275 \mathrm{~K}\end{array}$ & Snow water equivalent $<0.01 \mathrm{~m}$ & Daily TB $<300 \mathrm{~K}$ \\
\hline $\begin{array}{l}\text { ERA-Interim's daily average 2 m air } \\
\text { temperature }>273 \mathrm{~K}\end{array}$ & $\begin{array}{l}\text { ERA-Interim's daily average 2 m } \\
\text { air temperature }>273.5 \mathrm{~K} \\
\text { Orography (slope) }\end{array}$ & $\begin{array}{l}\text { Mask }<0.04 \\
\text { (from SMOS's L2 product) }\end{array}$ \\
\hline
\end{tabular}

* The slope is at the model T225 spectral horizontal resolution $(\sim 80 \mathrm{~km})$.

To do so, the covariance matrix $(\mathbf{R})$ of $F$ is computed. Next, the eigenvalue problem is solved:

$\mathbf{R C}=\mathbf{C} \boldsymbol{\Lambda}$,

where $\boldsymbol{\Lambda}$ is a diagonal matrix that contains $\boldsymbol{R}$ 's eigenvalues $\left(\lambda_{i}\right)$ and $\mathbf{C}$ is a matrix where its column vectors $\left(\boldsymbol{c}_{i}\right)$ are $\boldsymbol{R}$ 's eigenvectors, which correspond to $\lambda_{i}$.

Each eigenvalue corresponds to a variability mode and provides a measure of the total variance in $\boldsymbol{R}$ explained by the mode. Therefore, the biggest eigenvalue will correspond to the dominant variability mode. The eigenvector $\boldsymbol{c}_{i}$ is the spatial pattern $\left(\mathbf{P}_{i}\right)$ of the mode of variation $i$. The temporal evolution of a mode of variation is obtained by projecting the field $F$ onto the corresponding spatial pattern:

$\boldsymbol{\alpha}_{j}=F \boldsymbol{c}_{j}$

We will refer to these temporal series as the expansion coefficients (ECs). Positive values of ECs imply that there is no sign change in the spatial patterns. The EOF methodology is detailed in Björnsson and Venegas (1997).

We applied the EOF analysis to the error between measured and modelled TBs, to characterize it spatially and temporally. Identifying the main modes of variability of an error field allows us to propose and test hypotheses about its causes. We followed this approach to analyse the impact of forcing biases on modelled TBs. Other studies have also applied this methodology to error analysis. For example, Kanamitsu et al. (2010) analyse the impact of a regional model error on the inter-annual variability of a set of analysis fields.

\section{Results}

The temporal evolution and spatial structures of measured and modelled TBs are analysed in this section. This study follows the comparison between modelled and retrieved SSM (Polcher et al., 2016) and attempts to elucidate whether the difference found can be attributed either to the retrieval algorithm, which converts TBs into estimated SSM, or its modelled counterpart.

\subsection{Comparison of modelled and measured TBs}

The mean temporal and spatial correlations between measured and modelled TBs, over the IP from 2010 to 2012, are shown in Table 4. Values from the SSM comparison performed by Polcher et al. (2016) are also included. The differences between spatial and temporal correlations are already apparent and warrant separate analyses as a first step.

\subsubsection{Temporal correlation}

Figure 1 shows the temporal correlation between measured and modelled daily TBs for the horizontal and vertical polarizations. Both polarizations show a good agreement between models and observations in their temporal evolution, with values above 0.7 over a large part of the IP. This can be explained by the strong annual cycle imposed by the surface temperature, but more important are the quick responses of temperature and emissivity to precipitation events, which drive TB's fast variations and correspond to the synoptic variability of the signal. The high correlations indicate that it is well captured by both models. It confirms our hypothesis (Sect. 3.2.1) that the temporal correlation of TB is driven by the synoptic variability, as demonstrated in the SSM comparison performed by Polcher et al. (2016). Most of the areas with lower correlations correspond to mountain ranges. Relief effects on MW radiometry over land (Mätzler and Standley, 2000) are a difficult remote-sensing problem and, thus, discrepancies are expected. In fact, the lowest correlations (0.3 to 0.6) appear over some areas of the Pyrenees. Other examples are the Iberian System and the Cantabrian Mountains, located over the north-eastern and northern regions of the peninsula, respectively.

There are no large differences between the temporal correlation maps of $\mathrm{TB}_{\mathrm{OR}}$ and $\mathrm{TB}_{\mathrm{HT}}$ with $\mathrm{TB}_{\mathrm{SM}}$ (Fig. 1). Since the same forcing was used, the two LSMs share the same synoptic variability from the ERA-Interim reanalysis. However, Fig. 1 shows that the synoptic variability of H-TESSEL leads to slightly higher correlation values than ORCHIDEE's, especially over the northern part of the IP. 
(a) ORCHIDEE-SMOS (TBH)

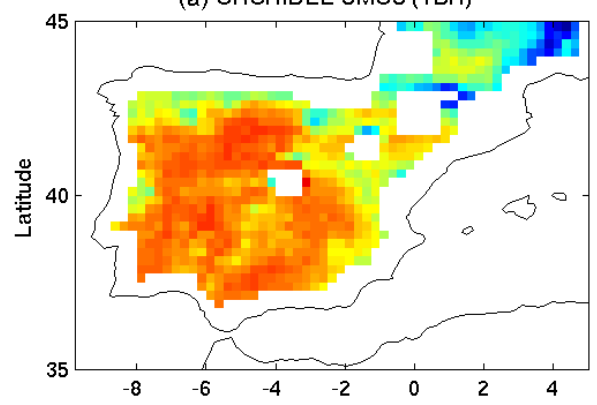

(c) HTESSEL-SMOS (TBH)

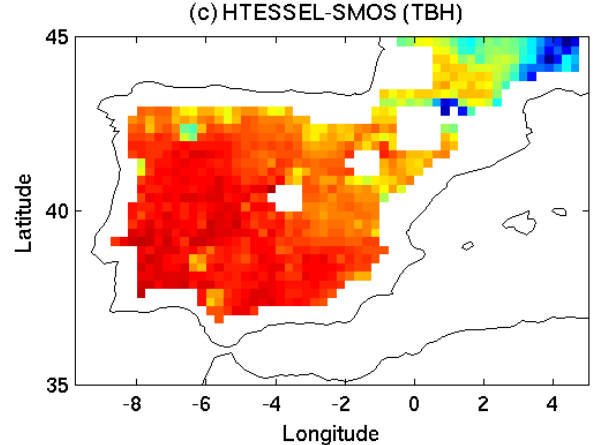

(b) ORCHIDEE-SMOS (TBV)

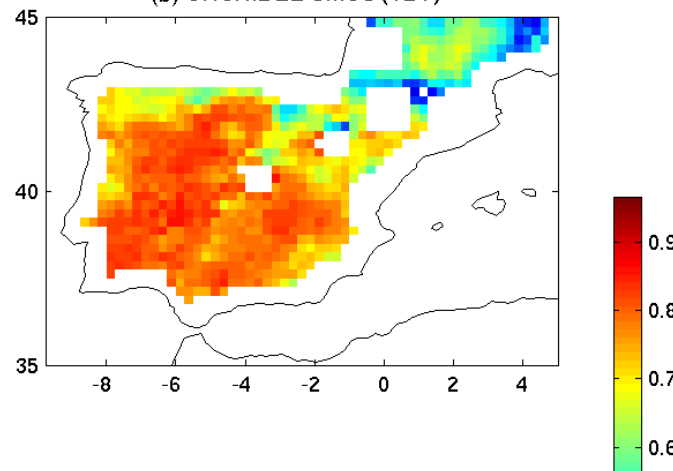

(d) HTESSEL-SMOS (TBV)

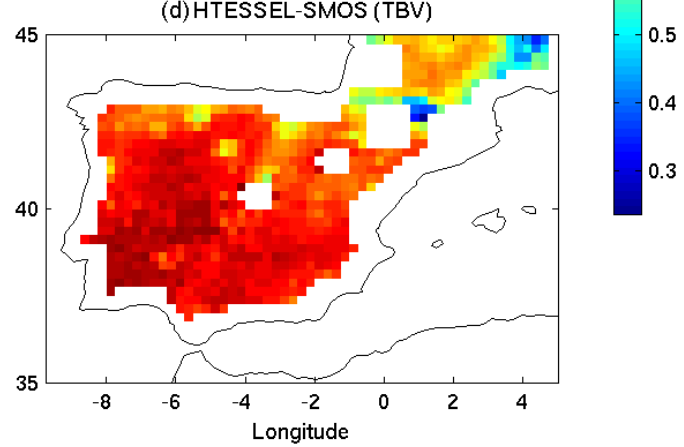

Figure 1. Temporal correlation between modelled and measured TBs from 2010 to 2012. TBH and TBV correspond to the horizontal and vertical polarizations, respectively.

Table 4. Mean temporal and spatial correlations for SSM (Polcher et al., 2016) and the horizontal and vertical polarizations of TBs over the Iberian Peninsula from 2010 to 2012.

\begin{tabular}{lcc|cc}
\hline & \multicolumn{2}{c|}{ Temporal } & \multicolumn{2}{c}{ Spatial } \\
\cline { 2 - 5 } & Horizontal & Vertical & Horizontal & Vertical \\
\hline TB $_{\text {OR vs. TB }}$ TB & 0.75 & 0.76 & 0.20 & 0.30 \\
TB $_{\text {HT vs. TB }}$ SM & 0.82 & 0.82 & 0.24 & 0.29 \\
TB $_{\text {HT(VC) vs. TB }}$ & - & - & 0.17 & 0.36 \\
TB $_{\text {OR(SD) vs. TB }}$ & - & - & 0.22 & 0.33 \\
TB $_{\text {OR(FW) vs. TB }}$ & - & - & 0.20 & 0.30 \\
SSM $_{\text {OR vs. SSM }}$ & - & \multirow{2}{*}{0.81} & & \multicolumn{2}{c}{0.28} \\
\hline
\end{tabular}

\subsubsection{Spatial correlation}

For clarity, the five daily spatial correlations are averaged per season and the distribution of values obtained is represented in boxplot form in Fig. 2. In general, the correlation is poor throughout the year. Although maxima are around 0.6, the annual mean ranges between 0.2 and 0.3 (Table 4). This implies that the spatial structures from both modelled TBs are not consistent with those observed by SMOS. We would like to point out the seasonality in the correlation. The lowest correlations occur during winter, where even negative values are obtained. These improve during spring and summer, and weaken again in autumn. Moreover, winter and autumn generally show larger ranges of variability and, thus, a wider dispersion of the data than spring and summer. Figure 2 also shows that the vertical polarization has systematically higher mean correlations than the horizontal one, except for the winter season. Finally, there is no significant difference in the correlation of $\mathrm{TB}_{\mathrm{SM}}$ with either modelled $\mathrm{TB}$, as has already been noted for the temporal correlation.

\subsection{Spatial and temporal characterization of the TB error}

The spatio-temporal variability of the error between modelled and measured TBs is studied to better understand the poor consistency of their spatial structures. We want to analyse whether this difference can be related to some physical process which might be incorrectly represented in both models. For this, an EOF analysis of the TB errors $\left(\mathrm{TB}_{\mathrm{OR}}-\mathrm{TB}_{\mathrm{SM}}\right.$ and $\left.\mathrm{TB}_{\mathrm{HT}}-\mathrm{TB}_{\mathrm{SM}}\right)$ is carried out.

\subsubsection{TB error}

\section{Spatial patterns}

Figure 3 shows the spatial patterns of the first two EOF variation modes corresponding to the TB error of ORCHIDEE $\left(\mathrm{TB}_{\mathrm{OR}}-\mathrm{TB}_{\mathrm{SM}}\right)$, for the horizontal and vertical polarizations. The variance explained by each mode is also provided as a percentage in brackets. The total variance explained by the patterns of the first variation mode is above $30 \%$ in both 


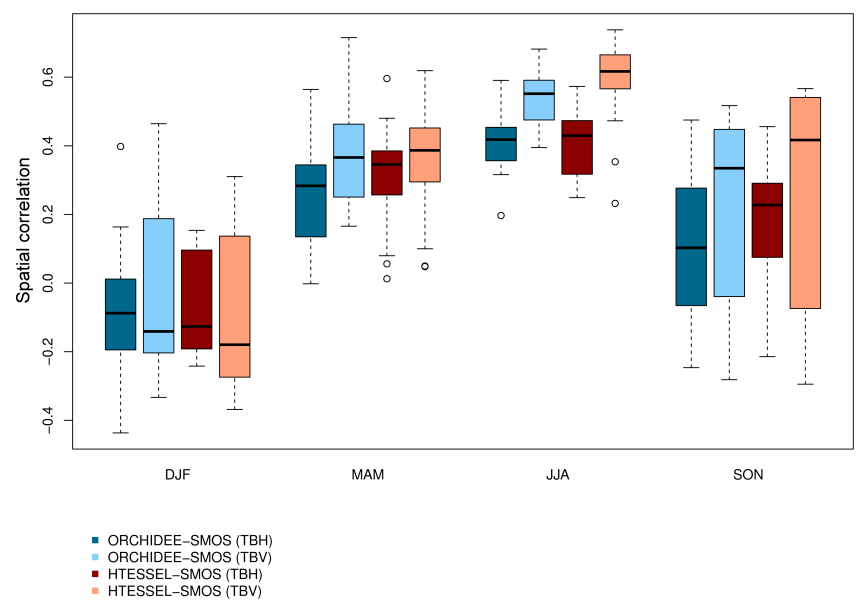

Figure 2. Boxplot showing the annual cycle of the spatial correlation between modelled and measured TBs over the Iberian Peninsula from 2010 to 2012. TBH and TBV correspond to the horizontal and vertical polarizations, respectively. Values have been grouped per season: winter (DJF), spring (MAM), summer (JJA), and autumn (SON).

Table 5. Spatial correlation for the first and second variation modes of the EOF analyses performed for the difference between modelled and measured TBs. TBH and TBV correspond to the horizontal and vertical polarizations, respectively.

\begin{tabular}{lcc}
\hline & Mode 1 & Mode 2 \\
\hline $\mathrm{TB}_{\mathrm{OR}}-\mathrm{TB}_{\mathrm{SM}}(\mathrm{TBH}) \mathrm{vs.}$ & 0.99 & 0.97 \\
$\mathrm{~TB}_{\mathrm{OR}}-\mathrm{TB}_{\mathrm{SM}}(\mathrm{TBV})$ & & \\
$\mathrm{TB}_{\mathrm{HT}}-\mathrm{TB}_{\mathrm{SM}}(\mathrm{TBH}) \mathrm{vs.}$ & 0.86 & 0.75 \\
$\mathrm{~TB}_{\mathrm{HT}}-\mathrm{TB}_{\mathrm{SM}}(\mathrm{TBV})$ & & \\
$\mathrm{TB}_{\mathrm{OR}}-\mathrm{TB}_{\mathrm{SM}}(\mathrm{TBH}) \mathrm{vs.}$ & 0.92 & 0.69 \\
$\mathrm{~TB}_{\mathrm{HT}}-\mathrm{TB}_{\mathrm{SM}}(\mathrm{TBH})$ & & \\
$\mathrm{TB}_{\mathrm{OR}}-\mathrm{TB}_{\mathrm{SM}}(\mathrm{TBV}) \mathrm{vs}$. & 0.73 & 0.48 \\
$\mathrm{~TB}_{\mathrm{HT}}-\mathrm{TB}_{\mathrm{SM}}(\mathrm{TBV})$ & & \\
\hline
\end{tabular}

polarizations: $36 \%$ (horizontal) and $31 \%$ (vertical). These two patterns show a similar structure characterized by high values over the south-west and a smaller area further north of the IP, which weaken as they extend through the rest of the peninsula. This similarity is confirmed by their high spatial correlation, which is 0.99 (Table 5). The second variation mode exhibits a structure that is also maximum over the south-west of the IP in both polarizations. However, the total variance explained has decreased to 6 and $7 \%$ (horizontal and vertical polarizations, respectively).

Figure 4 is equivalent to Fig. 3, but presents the TB error of H-TESSEL $\left(\mathrm{TB}_{\mathrm{HT}}-\mathrm{TB}_{\mathrm{SM}}\right)$. The variance fractions explained by the first EOF mode are 30 and $18 \%$ for the horizontal and vertical polarizations, which are lower than those obtained for the TB error of ORCHIDEE. As in Fig. 3, the first variation modes show similar spatial structures, which are highly spatially correlated $(0.86$, Table 5$)$. It is interest- ing to note that this structure coincides with the one identified for the TB error of ORCHIDEE (Fig. 3a and c). This is confirmed by the high correlation obtained between the patterns of the two errors: 0.92 and 0.73 for the horizontal and vertical polarizations, respectively (Table 5). The second variation mode of H-TESSEL's TB error explains $8 \%$ (horizontal polarization) and $12 \%$ (vertical polarization). The horizontal polarization pattern shows that the error is maximum over the south-western region of the IP, while the vertical polarization pattern does not show a clear structure. In contrast to the first variation mode, patterns from the second one show larger differences with the patterns depicted by the TB error of ORCHIDEE.

\section{Expansion coefficients}

Figure 5 shows the ECs of the first EOF variation mode of both TB errors: in other words, the projection of the error time series onto the EOF pattern, summarizing how much the error field varies according to the pattern.

The four series show a strong annual variation which peaks in autumn. High values are also observed in December 2012 and during the winter of 2010-2011. It should be noted that the behaviour of the ECs coincides with the marked seasonality shown in Fig. 2 and, thus, reinforces our observation that modelled TB patterns have their strongest disagreement with SMOS measurements in autumn and winter. The ECs of the second EOF variation mode of each TB error have not been included in Fig. 5, because the spatial patterns of each error differ between them. Nevertheless, it is important to note that they show variations at a higher frequency than those from the first mode.

Two conclusions can be drawn from these results.

First, the largest spatially coherent error identified in Figs. 3 and $4 \mathrm{a}$ and $\mathrm{c}$ is dominated by the slow-varying component of the TB signals, which is driven by the annual cycle. At first sight, this might seem to contradict the temporal correlation analysis (Fig. 1). However, it shows that the slow (annual cycle) and fast (synoptic variability) components of TBs show different behaviours.

Second, modelled TBs are warmer than measured ones over the south-western IP during autumn and winter, revealed by the first EOF patterns and their oscillations (Figs. 3 to 5). To further analyse this result, we looked at ECMWF's mean error from the months of November 2010 to 2012. This diagnostic consists of the time-averaged geographical mean of the difference between SMOS-measured TBs and modelled ones using the CMEM and H-TESSEL's surface state variables (Fig. 6). For all 3 years we see a contrast between the error over the north-western region of the IP (in an orange colour) and over the south-western region and a smaller area further north (in a blue colour). According to this, measured TBs are warmer than modelled ones over the north-west of the IP during these three periods, while modelled TBs are warmer than SMOS's over the south-west of the IP. This is 
(a) P1 TBH (36 \%)

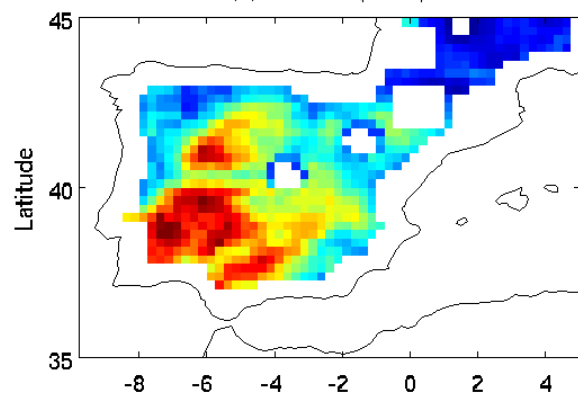

(c) P1 TBV (31\%)

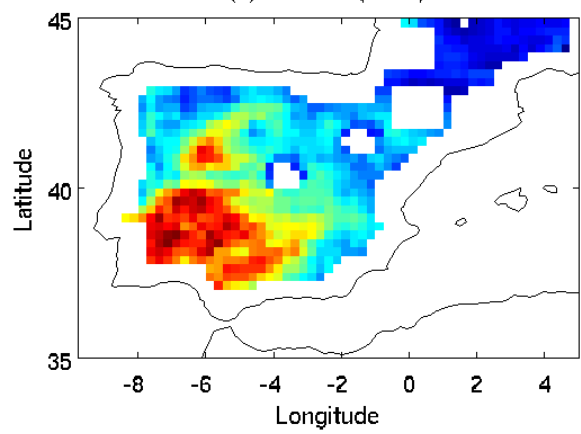

(b) P2 TBH (6\%)

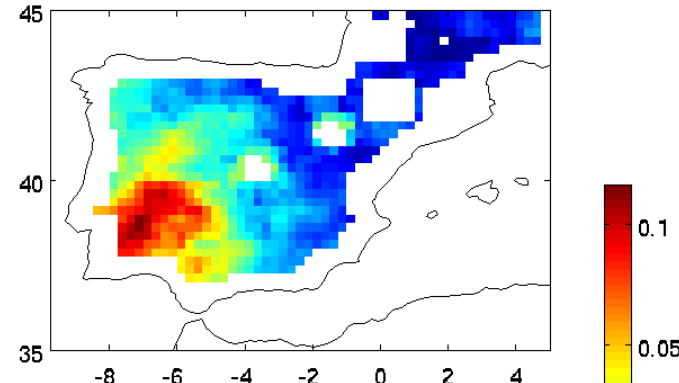

(d) P2 TBV (7 \%)

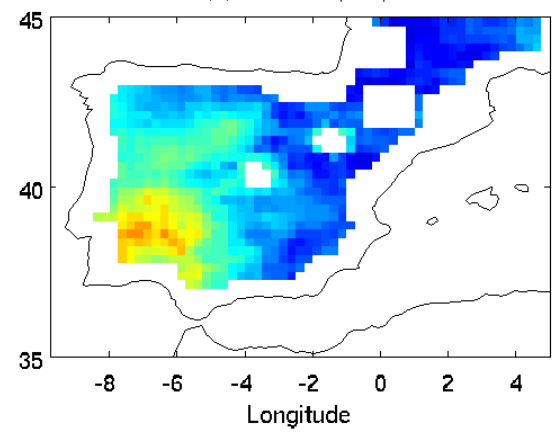

0.1

0.05

0

$-0.05$

Figure 3. Spatial patterns associated with the first two EOF variation modes (P1 and P2) of the difference between modelled TB (ORCHIDEE) and measured TB (SMOS). TBH and TBV correspond to the horizontal and vertical polarizations, respectively. The percentage of variance explained by each mode is included in brackets.

(a) P1 TBH (30\%)

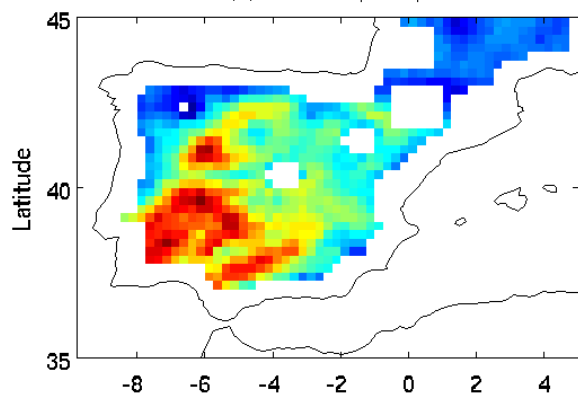

(c) P1 TBV (18\%)

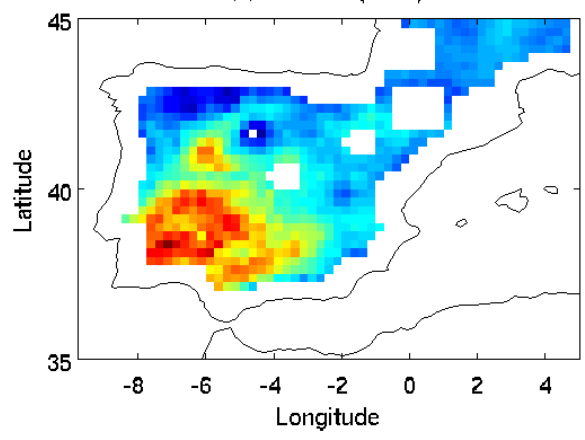

(b) P2 TBH (8\%)

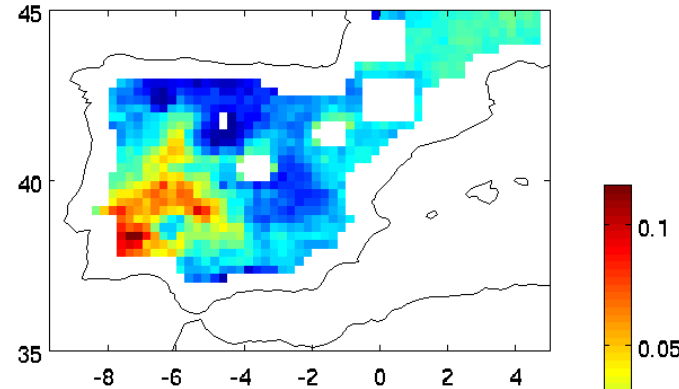

(d) P2 TBV (12\%)

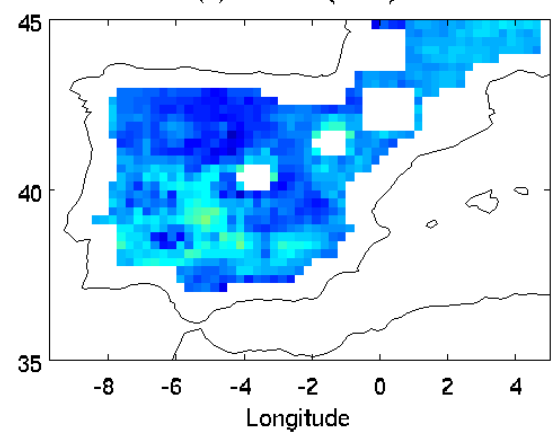

0.1

0.05

0

$-0.05$

Figure 4. As Fig. 3 but for H-TESSEL. 
Table 6. Possible explanations studied and proposed to analyse the dominant mode of the error between measured and modelled TBs. The paper's section where these are analysed has been included.

\begin{tabular}{|c|c|c|c|c|}
\hline \multicolumn{3}{|l|}{ Hypotheses } & \multirow{2}{*}{$\begin{array}{l}\text { Outcome (test) } \\
\text { Discarded } \\
\text { (EOF analysis*) }\end{array}$} & \multirow{2}{*}{$\begin{array}{l}\text { Section } \\
4.2 .2\end{array}$} \\
\hline Biases in precipitation forcing & & & & \\
\hline Errors in LST modelling & & & $\begin{array}{l}\text { Discarded (EOF analysis* and annual } \\
\text { cycle over the southern and northern IP) }\end{array}$ & 4.2 .2 and 4.3 \\
\hline \multirow[t]{6}{*}{ CMEM configuration } & Vegetation cover & & $\begin{array}{l}\text { Discarded (EOF analysis* and } \\
\text { spatial correlation) }\end{array}$ & \multirow[t]{2}{*}{4.2 .3} \\
\hline & Soil discretization & & Discarded (EOF analysis*) & \\
\hline & \multirow[t]{4}{*}{$\varepsilon$ parameterization } & $\begin{array}{l}\text { Combined effect of the Fresnel law } \\
\text { and Wigneron et al. (2001) } \\
\text { to estimate } \varepsilon_{\mathrm{S}} \text { and } T_{\text {eff }}\end{array}$ & $\begin{array}{l}\text { Discarded (EOF analysis* and } \\
\text { spatial correlation) }\end{array}$ & \\
\hline & & $\epsilon$ estimation & Proposed to study & 5 \\
\hline & & $\tau_{\mathrm{veg}}$ estimation & Proposed to study & \\
\hline & & $\varepsilon_{\mathrm{r}}$ estimation & Proposed to study & \\
\hline $\begin{array}{l}\text { Modelled LAI } \\
\text { Rainfall interception } \\
\text { Attenuation effect of litter in measured TB } \\
\text { LSMs' subgrid process simplifications } \\
\text { Instrumental issues (RFIs) }\end{array}$ & & & $\begin{array}{l}\text { Discarded } \\
\text { Discarded } \\
\text { Discarded } \\
\text { Discarded } \\
\text { Discarded }\end{array}$ & \\
\hline
\end{tabular}

* EOF analysis $\rightarrow$ incompatible spatio-temporal variability of errors.

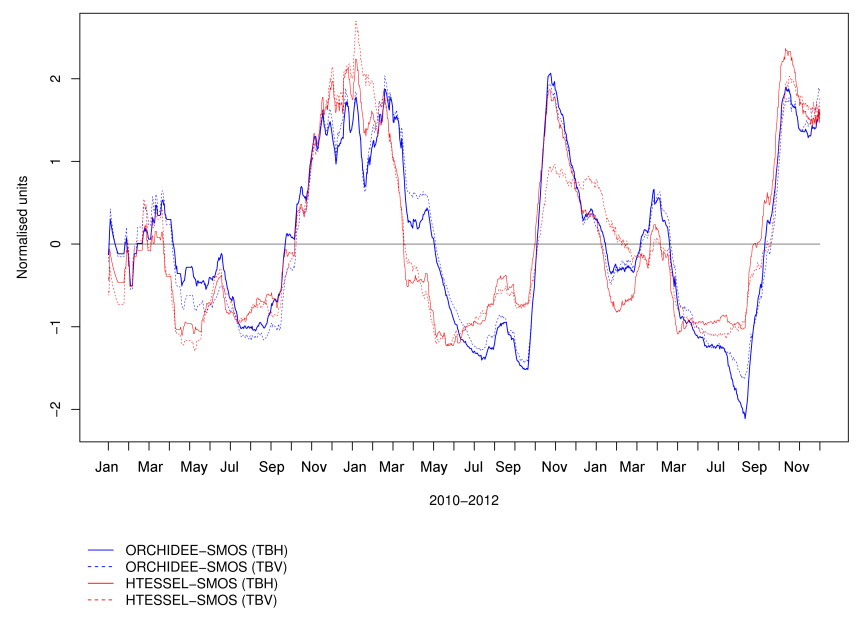

Figure 5. Temporal evolution of the expansion coefficients corresponding to the first EOF variation mode of the TB errors (ORCHIDEE vs. SMOS and H-TESSEL vs. SMOS) over the Iberian Peninsula. Values have been normalized using the standardization method. TBH and TBV correspond to the horizontal and vertical polarizations, respectively.

in good agreement with the behaviour described by the first EOF variation mode of both TB errors (Figs. 3 and $4 \mathrm{a}$ and c). It should be noted that the mean error shows a global bias between the spatial patterns of measured and modelled TBs. However, only the IP is represented in this figure to show clearly the spatial structures.
To summarize, the EOF analyses of the ORCHIDEE and H-TESSEL TB errors identified a common dominant structure, which is maximum in the autumn and winter seasons over the south-west of the IP and a smaller area further north. It represents between 18 and $36 \%$ of the error depending on the modelled TB set considered and its polarization. Moreover, it corresponds well to the ECMWF mean error for the 2010-2012 November months.

\subsubsection{LST and precipitation errors}

Precipitation and LST data are used to explore possible causes of the difference between measured and modelled TBs. Errors are calculated with respect to independent datasets. The dominant error pattern of each variable is computed via EOF analysis and compared with the dominant pattern of the ORCHIDEE and H-TESSEL TB errors. If similarities can be identified, then possible causal links between these variables and the TB error can be explored.

The precipitation error is calculated as the difference between the $P$ provided by the ERA-Interim forcing and the E-OBS independent dataset. The LST errors are computed as the difference between modelled LST (from ORCHIDEE or H-TESSEL) and the EUMETSAT LandSAF product (http: //landsaf.meteo.pt).

\section{Spatial patterns}

The first EOF patterns of $P$ and LST errors are represented in Fig. 7, together with their explained variance. The precipitation error is common to both models as it originates in the 
(a) $2010(\mathrm{TBH})$

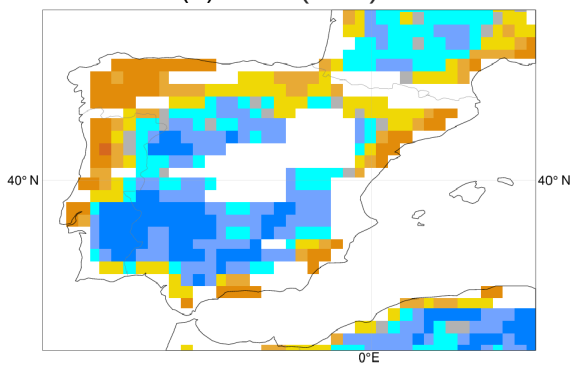

(c) $2011(\mathrm{TBH})$

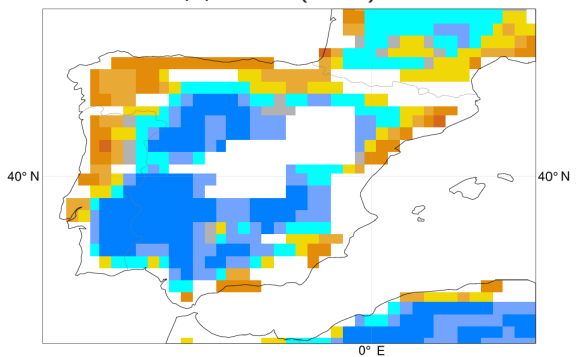

(e) $2012(\mathrm{TBH})$

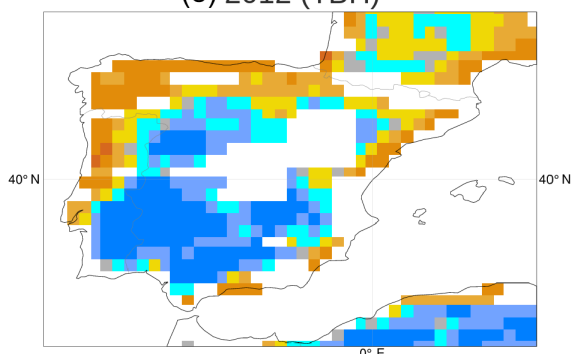

(b) 2010 (TBV)

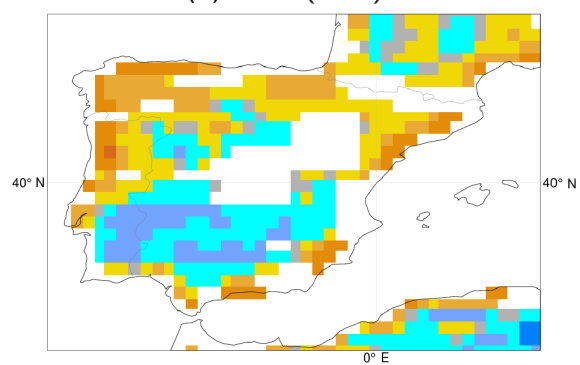

(d) 2011 (TBV)

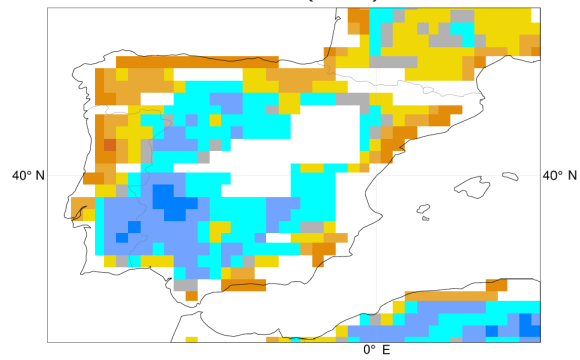

(f) 2012 (TBV)

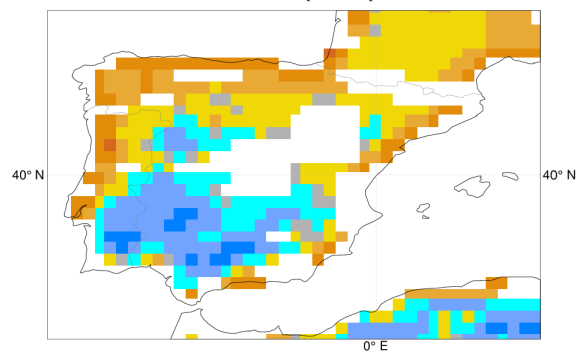

Figure 6. ECMWF's mean error (observation-model) from the months of November 2010 to 2012. TBH and TBV correspond to the horizontal and vertical polarizations, respectively.

selected forcing. The dominant spatial structure of this error, which represents only $15 \%$ of the total variance, has its maximum in the south-east of the IP and is different from the one found for TB. The error patterns from LST differ remarkably between the two models and do not seem related to the TB error. On the one hand, a north-south gradient is observed in ORCHIDEE's LST error (Fig. 7a), which is most likely explained by forcing-induced biases due to available energy affecting the LSM simulation. On the other hand, $\mathrm{H}$ TESSEL's LST error pattern (Fig. 7c) shows a gradient from east to west.

\section{Expansion coefficients}

The ECs corresponding to each of these patterns are presented in Fig. 8. Those for the precipitation error show a higher frequency variation than those of the LST and TB errors. ORCHIDEE's LST error behaves as expected from land-surface physics, with a maximum in summer when the largest amount of energy is absorbed by the surface and, thus, small errors in the energy balance translate into large temperature differences. This is not the case for H-TESSEL's LST error, whose ECs show higher frequency variation, with maxima in the autumn season and at the end of the winter in 2011 and 2012.

The dominant modes of variability of $P$ and LST errors show different spatial and temporal characteristics than the TB error dominant pattern. Neither the spatial structures nor their temporal evolution over the 2010 to 2012 period coincide. The TB errors show a strong annual variation which peaks in autumn and winter. The ECs of ORCHIDEE's LST error show a maximum in summer, while those for H-TESSEL's LST and $P$ errors are characterized by higher-frequency variations.

The difference between the EOF analyses' results of $P$, LST, and TB errors suggests that their error sources differ. Therefore, even though the products taken as a reference (EOBS and LandSAF) are affected by errors, these do not seem 
(a) LST [ORCHIDEE-LandSAF] $(21 \%)$

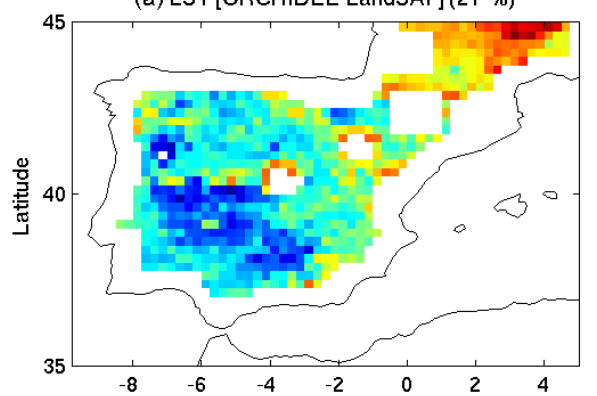

(c) LST [HTESSEL-LandSAF] $(17 \%)$

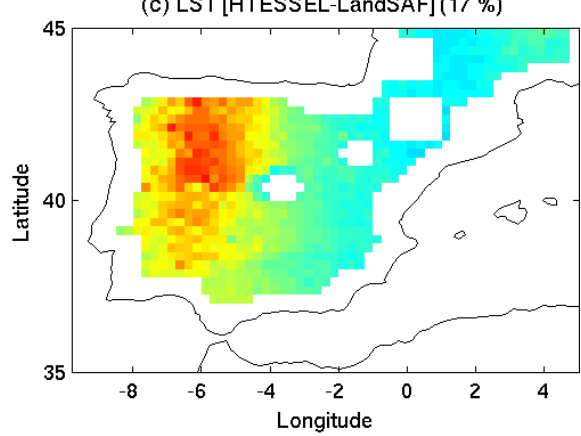

(b) Precipitation [ERA-EOBS] (15\%)

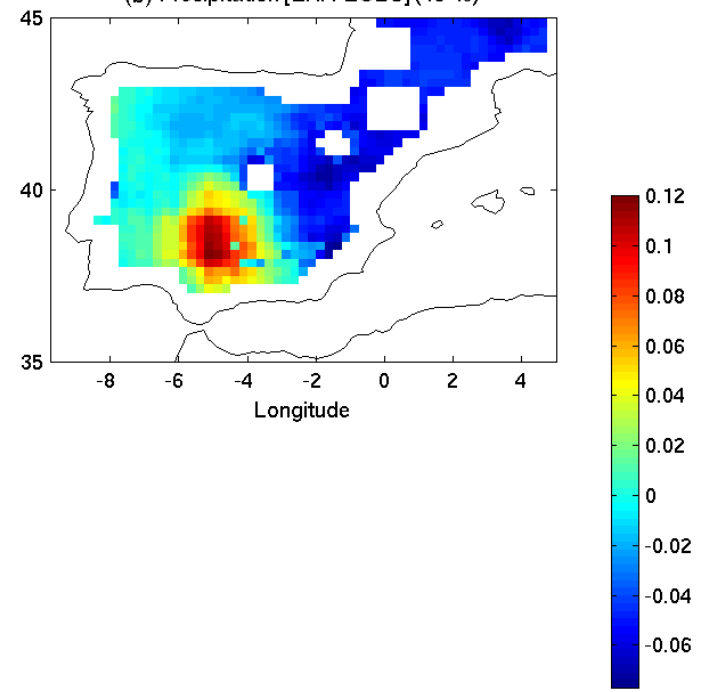

Figure 7. Spatial patterns from the first EOF variation mode of the LST and the precipitation errors. The percentage of variance explained by each mode is included in brackets.

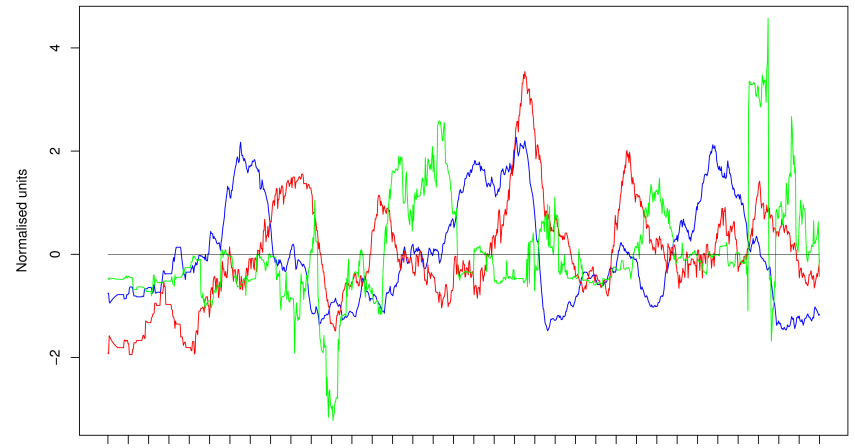

Jan Mar May Jul Sep Nov Jan Mar Mary Jul Sep Nov Jan Mar Mary Jul Sep Nov 2010-2012

— LST (ORCHIDEE-LandSAF) Precipitation (ERA-EOBS)

Figure 8. Temporal evolution of the expansion coefficients corresponding to the first EOF variation mode of the LST and the precipitation errors. As in Fig. 5, values have been normalized using the standardization method.

to be responsible for the dominant mode of the TB discrepancy. The EOF analysis excludes the hypothesis that biases in precipitation driving the models or errors in their surface temperature are the direct cause of the inconsistency in TB's spatial structures. The strong similarity of the TB errors in two quite different LSMs further strengthens the rejection of this hypothesis.

\subsubsection{Analysis of CMEM assumptions}

The CMEM is another candidate to explain the TB error since it is also a common element from both sets of modelled TBs. In fact, modelled TBs have been shown to be more sensitive to the configuration of the microwave model than to the LSM used (de Rosnay et al., 2009).

As explained in Sect. 2, we performed a sensitivity analysis to test whether certain CMEM parameterizations could explain the differences between measured and modelled TBs. As a result, three new sets of modelled TBs were estimated, $\mathrm{TB}_{\mathrm{HT}(\mathrm{VC})}, \mathrm{TB}_{\mathrm{OR}(\mathrm{SD})}$, and $\mathrm{TB}_{\mathrm{OR}(\mathrm{FW})}$, to evaluate the role of vegetation, vertical discretization, and the emissivity parameterization, respectively.

In the first place, $\mathrm{TB}_{\mathrm{HT}(\mathrm{VC})}$ shows similar mean spatial correlations with $\mathrm{TB}_{\mathrm{SM}}$ to the ones for $\mathrm{TB}_{\mathrm{HT}}$ and $\mathrm{TB}_{\mathrm{SM}}$ (Table 4). In addition, an EOF analysis of the difference between this new estimate and observed TBs (figure not included) shows similar spatial patterns to the ones identified in Fig. 4a and c, as well as a good agreement between their ECs.

In the second place, no significant differences were observed between $\mathrm{TB}_{\mathrm{OR}(\mathrm{SD})}$ and $\mathrm{TB}_{\mathrm{OR}}$ when compared to $\mathrm{TB}_{\mathrm{SM}}$. For instance, mean spatial correlations computed using $\mathrm{TB}_{\mathrm{OR}(\mathrm{SD})}$ and $\mathrm{TB}_{\mathrm{SM}}$ are 0.22 and 0.33 for the horizontal and vertical polarizations, which are similar to the values obtained for $\mathrm{TB}_{\mathrm{OR}}$ and $\mathrm{TB}_{\mathrm{SM}}$ (Table 4). 
(a) ORCHIDEE (TBH)

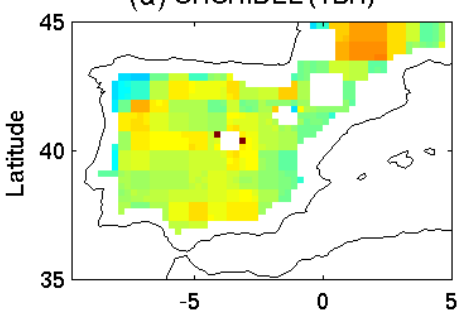

(d) ORCHIDEE (TBV)

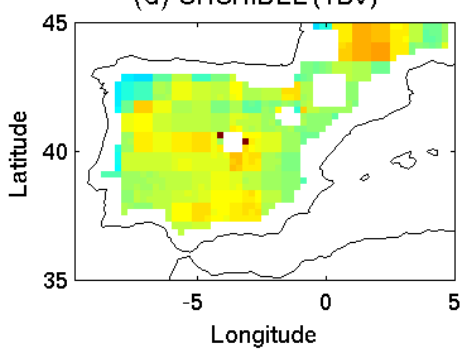

(b) HTESSEL (TBH)

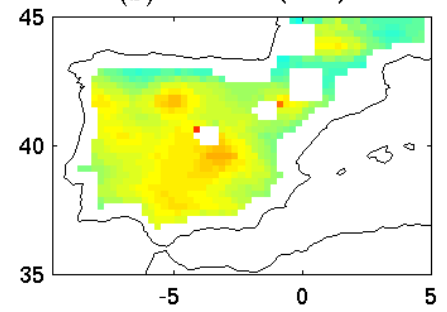

(e) HTESSEL (TBV)

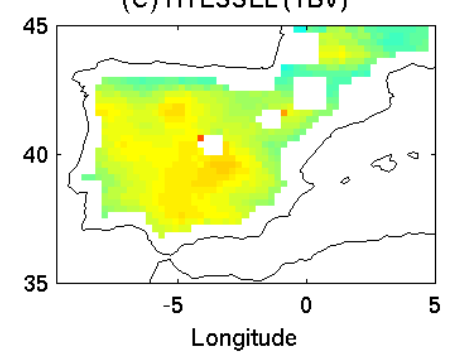

(c) SMOS (TBH)

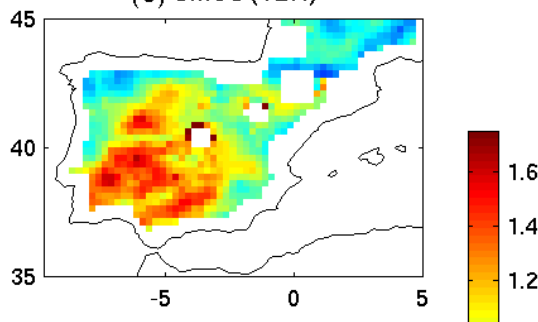

1.6

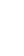

$-0.8$

(f) SMOS (TBV)

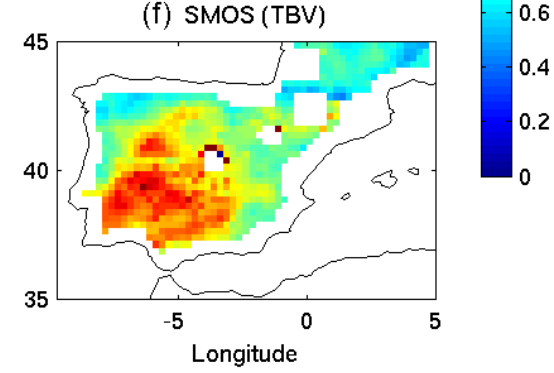

Figure 9. Normalized amplitude of the smoothed annual cycle of modelled and measured TBs: amplitude(TB)/TB. TBH and TBV correspond to the horizontal and vertical polarizations, respectively.

In the third place, an EOF analysis of the TB error computed using the $\mathrm{TB}_{\mathrm{OR}(\mathrm{FW})}$ and $\mathrm{TB}_{\mathrm{SM}}$ sets (figure not included) shows a similar dominant structure both in space and time to the one observed in Fig. 3a and c. In addition, similar spatial correlations between $\mathrm{TB}_{\mathrm{OR}(\mathrm{FW})}$ and $\mathrm{TB}_{\mathrm{SM}}$ to those from $\mathrm{TB}_{\mathrm{OR}}$ and $\mathrm{TB}_{\mathrm{SM}}$ are also found (Table 4).

As synthesized in Table 4, in the current state of CMEM the vegetation cover, the number of soil layers, and the $\varepsilon_{s}$ and $T_{\text {eff }}$ parameterizations can be discarded as the dominant factors responsible for the poor spatial correlation between modelled and SMOS TBs.

\subsection{Annual cycle of TBs}

The slow-varying component of the TB signals is analysed pixel by pixel, because it has been identified as the driver of the largest spatially coherent error structure between measured and modelled TBs (Fig. 5). For this matter, the mean annual cycle of each TB signal was computed for each pixel and then smoothed using a spline filter to remove submonthly fluctuations. The period of study is too short to ensure that a simple annual mean cycle will filter out highfrequency variations. In Fig. 9 the normalized amplitudes of the annual TB cycle are displayed.

The spatial structures shown in SMOS's maps (Fig. 9c and f) exhibit strong resemblances to those observed in the first EOF patterns of the TB error (Figs. 3 and $4 \mathrm{a}$ and c). However, this structure is not found in the maps corresponding to $\mathrm{TB}_{\mathrm{OR}}$ and $\mathrm{TB}_{\mathrm{HT}}$, where there is less contrast in the spatial distribution of the relative amplitude of the annual cycle.
This indicates that the LSMs combined with CMEM do not reproduce the annual cycle amplitude of TBs observed by SMOS.

To further analyse this result, two study areas are defined (Fig. 10). The first one is over the south-western IP $\left(7.5^{\circ} \mathrm{W}: 4^{\circ} \mathrm{W}, 40^{\circ} \mathrm{N}: 38^{\circ} \mathrm{N}\right)$ and corresponds to the part of the area where the largest differences in TB's normalized amplitudes are identified. The second one is the north-western region $\left(8.25^{\circ} \mathrm{W}: 6^{\circ} \mathrm{W}, 43^{\circ} \mathrm{N}: 41.75^{\circ} \mathrm{N}\right)$ of the IP and is chosen because it shows similar annual cycle amplitudes of TB in the two models and SMOS. In addition, the EOF analysis of the TB error showed opposite behaviours in these areas.

Figure 10 shows the smoothed annual cycle of the horizontal and vertical polarizations of the TB signals from both regions. The LST from the LandSAF product as well as those modelled by ORCHIDEE and H-TESSEL are also displayed because of their direct relation to TBs. The plots show that the TB's annual cycle behaviour differs between both regions and is not related to the LST errors obtained when comparing to the LandSAF product. Therefore, the processes responsible for the TB error are probably different in each one of them.

The following results can be extracted from the plot corresponding to the south-western area (Fig. 10a).

In winter, the difference between models is small compared to their relative warm bias when compared to SMOS. In summer, the agreement is relatively good, with observations lying within the spread of the models. This explains the result presented above, namely that the amplitude of the simulated annual cycle is smaller than for the remotely sensed 

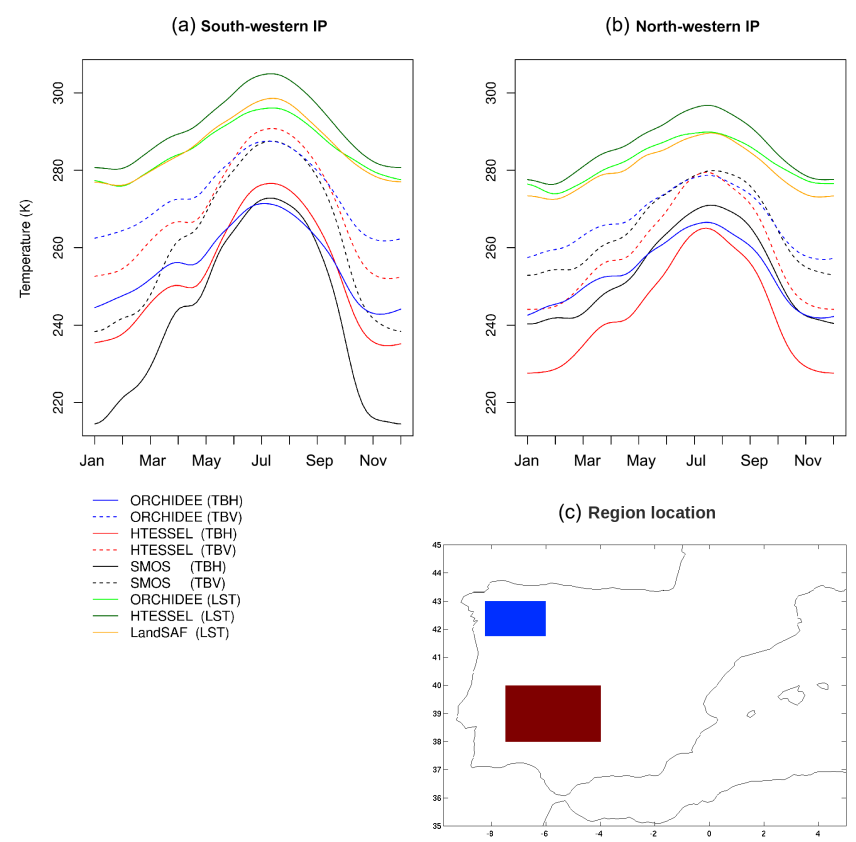

Figure 10. Smoothed annual cycle of $\mathrm{TB}_{\mathrm{SM}}, \mathrm{TB}_{\mathrm{OR}}$, and $\mathrm{TB}_{\mathrm{HT}}$, as well as of the LST signals from ORCHIDEE, H-TESSEL, and LandSAF over south-western (a) and north-western (b) regions of the Iberian Peninsula, from 2010 to 2012. The TBH and TBV correspond to the horizontal and vertical polarizations, respectively. The regions' location is shown in panel c: south-west (red) and northwest (blue).

TB. Examining the LST, one can note that the biases are relatively small and that ORCHIDEE generally matches the LandSAF product better, but H-TESSEL shows a larger and more correct amplitude of the annual cycle. This might explain why this model has the largest amplitude of TB in both polarizations, indicating that a large fraction of the error in the annual cycle of TB is caused by the emissivity simulated by CMEM given the surface states of both LSMs.

Over the north-western IP, SMOS observations are mostly within the uncertainty spanned by the two models. One notable exception is the summer period for the horizontal polarization where both models are cooler. Also in this region, the amplitude of TB in both polarizations is larger in H-TESSEL than ORCHIDEE and closer to that measured by SMOS. Again, this can be related to LST. Although ORCHIDEE has smaller biases, the H-TESSEL amplitude of the annual cycle is larger and closer to the observed one.

The strong difference in behaviour between the two selected regions in winter is already visible in the dominant EOF mode of the TB errors. The spatial patterns (Figs. 3 and 4) have different signs in the north-western and southwestern regions. For both regions, the LST biases of the LSMs do not show a clear relation to the simulated TBs. HTESSEL has the warmest surface temperatures but the lowest TBs, indicating that its state variables produce a lower emissivity than ORCHIDEE when processed by CMEM. On the other hand, the differences in annual amplitudes of LST could contribute to the differences in the amplitude of the simulated TB annual cycle. This is also supported by the fact that the dominant variation modes of LST errors are not related to those of TBs. This would indicate that the major contribution to the TB errors found for the models does not originate in their forcing or their ability to simulate the landsurface energy balance and temperature, but rather in the way CMEM simulates L-band emissivity based on their description of the surface state.

\section{Discussion}

This work complements with an analysis of TBs the study by Polcher et al. (2016), which compared the SSM product of SMOS with ORCHIDEE's modelled SSM. Both studies present a spatio-temporal correlation analysis and obtain similar results: a good agreement in temporal evolutions and a large mismatch between the spatial structures of measured and modelled SSM and TB.

The temporal correlation between $\mathrm{TB}_{\mathrm{OR}}$ and $\mathrm{TB}_{\mathrm{SM}}$ is very similar to that between retrieved (SMOS) and modelled (ORCHIDEE) SSM (Table 4). In addition, both variables show lower correlations over mountain ranges. As noted for SSM, the temporal correlation is mainly driven by its fast-varying component and is not very sensitive to the annual cycle (Polcher et al., 2016).

Spatial correlations are low for both variables, indicating an inconsistency between the spatial structures of measured and modelled data. Polcher et al. (2016) showed that the spatial correlation between retrieved and modelled SSM is worse for the SSM's slow-varying component than for its fast-varying component. This can be due to the fact that the largest spatially coherent error between measured and modelled TBs is dominated by their slow-varying component, as shown in this paper.

The EOF analysis presented here identified a dominant structure over the south-western IP using both sets of modelled TBs, which explains a large fraction of the TB error. This structure differs from the error characterization of the SSM comparison, which showed the largest discrepancies between modelled and retrieved SSM over the north-western IP. In fact, only weak differences were found for SSM over the south-western region (Polcher et al., 2016). These results indicate that the transfer functions used by SMOS to derive SSM from observed TBs or CMEM, which estimates TBs from modelled SSM (together with other state variables), play an important role and have to be better understood in order to explain the differences between the SMOS observations and the simulated surface states.

None of the hypotheses tested to identify a methodological weakness in the forcing of both LSMs or the configuration of CMEM, which would explain this common error, 
was conclusive. The differences in TB between the LSMs and SMOS are noteworthy and we believe that understanding them should be a priority for the community to achieve a better usage of these observations. As the LSMs used here are very different in their conception, it is unlikely that they will produce the same systematic SSM bias, which would explain the large discrepancy in the south-west of the IP during winter. On the other hand, processes which are not represented with enough detail in both schemes could explain the error and need to be analysed as to their potential to explain the discrepancies.

- In the first place, it is interesting to study the leaf area index (LAI), because it is linked to the seasonal cycle of vegetation. It may, therefore, reveal some underestimated effects of vegetation dynamics on modelled TBs, which could be related, to a certain extent, to the seasonality identified in the dominant structure of the TB error. In addition, the LAI is a key component in the CMEM parameterization of $\tau_{\text {veg. }}$. However, the areas of the IP where the TB error is largest are those of least vegetation. Therefore, in our opinion, modelled LAI is not likely to be the main cause of the differences in TB's spatial structures.

- In the second place, assumptions made in the modelling of rainfall interception may also explain some differences between modelled and measured TBs, in particular, those shown in Fig. 10b over the north-western region of the IP. This region is characterized by an oceanic climate and, thus, wet winters and mild summers, with high precipitation and rainfall often occurring as drizzle. In contrast to the southern region, there is more vegetation and, thus, rainfall interception plays a key role over this area and may be of interest to revise how this process is modelled. However, the IP region with strong interception is not the one with the largest TB error. The error over the south-western region is larger than over the north-western region, as shown by the EOF analysis.

- In the third place, the attenuation effect of litter on the soil and its interception of water could also explain differences obtained between modelled and measured TBs, since it is not taken into account by models, but is part of satellite observations. However, we believe that probably it would not cause an impact structured as the one observed over the south-western area of the IP without affecting other regions. Indeed, this process would be strongest in regions with dense vegetation.

- Finally, issues related to the fundamental simplification of subgrid processes in LSMs may also contribute to the inconsistency between the spatial structures of modelled and measured TBs. For instance, LSMs do not represent small-scale features such as open water in lakes and rivers, swamps, irrigated areas, or other water ponded on the surface, and could contribute strongly to L-band emissivity of the surface. Assumptions made by LSMs could neglect key issues from the small scale which could be carried over to the large scale of TBs. For the moment, we do not see why these simplifications of LSMs would have the strongest impact in the southwest of the IP.

Instrumental issues from SMOS could also explain the differences in TB spatial structures, in case these are not of a climatological or geophysical nature. For example, one of the most important causes of noise in SMOS surface soil moisture is radio-frequency interferences (RFIs). DaganzoEusebio et al. (2013) describe their effect on SMOS data. Some of them are difficult to detect and, thus, RFIs may not be properly filtered out. For instance, Dente et al. (2012) identified an irregular angular pattern in the TBs affecting data from the L1C product used to retrieve soil moisture. In their opinion, this was caused by weak RFIs which were not correctly filtered. Another explanation could be antenna pattern errors as SMOS TB seasonal and latitudinal drifts detailed in Oliva et al. (2013). However, RFIs are not likely to be the main cause of the differences between measured and modelled TBs, because the main spatial structure identified in both TB errors is found to be dominated by the brightness temperature's annual cycle. This suggests that it contains a geophysical signal.

In our opinion, further analyses should be carried out regarding the CMEM assumptions concerning emissivity. According to Jones et al. (2004), the soil moisture and vegetation water content have a significant effect on the sensitivity of TB at the top of the atmosphere. However, they impact microwave emission in different ways. On the one hand, an increase in soil moisture results in a higher soil dielectric constant $(\epsilon)$ and, thus, in lower emissivities. On the other hand, an increase in the vegetation water content raises the scatter and the absorption, increasing the emission. The $\epsilon$ is key in the computation of emissivity, while the vegetation optical depth $\left(\tau_{\text {veg }}\right)$ is closely related to the vegetation water content. Both variables are modelled in CMEM and the same parameterization has been used to estimate the two sets of modelled TBs: Wang and Schmugge (1980) for $\epsilon$ and Wigneron et al. (2007) for $\tau_{\text {veg. }}$. Furthermore, the same parameterization has been used to model the rough surface emissivity $\left(\varepsilon_{\mathrm{r}}\right)$ in both cases: Wigneron et al. (2001). Considering that similar spatial patterns were obtained for the TB error using two different LSMs, focus should be placed on the above-mentioned variables $\left(\epsilon, \tau_{\mathrm{veg}}\right.$, and $\left.\varepsilon_{\mathrm{r}}\right)$ in CMEM. We suggest prioritizing the analysis of the relationship between the vegetation water content and TB because of the role the vegetation opacity model plays in CMEM's configuration, as shown in de Rosnay et al. (2009). In addition, no significant differences were observed between modelled and retrieved SSM over the south-western IP (Polcher et al., 2016), where the maximum 
TB error was identified. This reassures our suggestion of prioritizing $\tau_{\text {veg }}$ with respect to $\epsilon$, since the latter is directly related to SSM.

The hypotheses analysed to identify the cause of TB's error dominant mode, as well as those proposed to study it, are listed in Table 6. The conclusion obtained for each analysis is also included.

\section{Conclusions}

TBs of the SMOS Level 1C product were compared to two sets of modelled TBs. The latter were obtained using simulated state variables (from the ORCHIDEE and H-TESSEL LSMs) and a radiative transfer model, CMEM. The study was carried out over the Iberian Peninsula (IP) for the period 2010 to 2012.

On the one hand, a temporal correlation analysis between measured and modelled data shows that there is a good agreement in their temporal evolution. However, this diagnostic is mainly driven by the TB's signal synoptic variability, as occurs with SSM (Polcher et al., 2016). On the other hand, a spatial correlation analysis detected a large mismatch between the TB spatial structures provided by models and observations.

An EOF analysis of the error between modelled and measured TBs suggests that the inconsistency is not limited to a particular LSM. It is dominated by the TB slow-varying component, peaking in autumn and winter. In addition, modelled TBs are larger than SMOS measurements during these seasons over the dominant error structure detected. This structure explains between 18 and $36 \%$ of the TB error variance, depending on the LSM and polarization. Therefore, there is a high percentage of the error (between 82 and $64 \%$ ) that shows structures which have to be analysed and explained. Since these are not present in both LSMs, they are of lower priority and have not been approached in this study.

Forcing-induced biases are discarded as the main cause of the spatial inconsistency in TBs after computing the dominant error structures of precipitation and land-surface temperature (LST). Nevertheless, the degree of accuracy of the forcing cannot be fully established because of scale issues and the lack of sufficient independent measurements. The difference in TBs' spatial structures could also be thought of as a combination of non-linear relations between errors in precipitation and LST, but this is beyond the scope of this paper.

Assumptions made in certain CMEM parameterizations are also discarded as the main source of the spatial inconsistency between measured and modelled TBs: the vegetation cover input; the number of soil layers defined; and some parameterizations to compute the smooth surface emissivity (Fresnel law and Wilheit, 1978) and the effective temperature (Wigneron et al., 2001, and the temperature profile).
Previous studies found differences between the spatial structures of modelled and retrieved SSM (Parrens et al., 2012; Polcher et al., 2016). This paper shows that these structures are not consistent also when comparing modelled and observed TBs. In addition, this issue is amplified for the TBs compared to SSM, because the latter are bounded by zero and saturation. This could explain the generally better spatial correlation for SSM in winter, when it reaches saturation in large parts of the IP. Although this study is limited to the IP, differences in spatial structures occur at a global scale. We would like to draw the reader's attention to the fact that TBs are not only the main input of the SMOS soil moisture retrieval algorithm, but that they are used to retrieve other variables, like vegetation optical depth or salinity. We believe that analysing the spatial inconsistencies between modelled and measured TBs is important, as these can affect the estimation of geophysical variables and TB assimilation in operational models, as well as result in misleading validation studies. Therefore, obtaining the spatial contrast of measured TBs in models is a challenge which, in our opinion, deserves a higher priority in the community.

\section{Data availability}

The observational datasets used in the present study can be accessed freely from their original source: SMOS L1C (MIR SCLF1C, version 505): https://smos-ds-02.eo.esa. int. The post-processing performed before comparison to CMEM output is described in Sect. 2.1. E-OBS: http://www. ecad.eu/download/ensembles/download.php; LandSAF LST: http://landsaf.ipma.pt/; ERA-Interim: http://www.ecmwf.int/ en/research/climate-reanalysis/era-interim.

The simulations were produced specifically for this study but can be reproduced using the corresponding release of the models: ORCHIDEE: https://forge.ipsl.jussieu. fr/orchidee (release no. 3400); CMEM: https://software. ecmwf.int/wiki/display/LDAS/CMEM (version4.1); HTESSEL: http://www.ecmwf.int (cycle38r2).

Acknowledgement. The authors would like to thank Filipe Aires and Jean-Pierre Wigneron for their helpful comments. We are also very thankful to one anonymous reviewer whose comments have greatly improved the document. This work contributes to the FP7 Earth2Observe project under grant agreement no. 603608.

Edited by: A. Weerts

Reviewed by: R. S. Westerhoff and Y. Zeng

\section{References}

Albergel, C., Zakharova, E., Calvet, J. C., Zribi, M., Pardé, M., Wigneron, J. P., Novello, N., Kerr, Y., Mialon, A., and Fritz, N.: A first assessment of the SMOS data in southwestern France using in situ and airborne soil moisture estimates: The CAROLS 
airborne campaign, Remote Sens. Environ., 115, 2718-2728, 2011.

Balsamo, G., Vitterbo, P., Beljaars, A., van den Hurk, B., Hirschi, M., Betts, A. K., and Scipal, K.: A Revised Hydrology for the ECMWF Model: Verification from Field Site to Terrestrial Water Storage and Impact in the Integrated Forecast System, J. Hydrometeorol., 10, 623-643, doi:10.1175/2008JHM1068.1, 2009.

Baroni, G., Facchi, A., Gandolfi, C., and Ortuani, B.: Analysis of the performances of methods for the evaluation of soil hydraulic parameters and of their application in two hydrological models, in: Irrigation in Mediterranean agriculture: challenges and innovation for the next decades, Bari: CIHEAM, edited by: Santini, A., Lamaddalena, N., Severino, G., and Palladino, M., Options Méditerranéennes: Série A. Séminaires Méditerranéens; no. 84, 213-222, 2008.

Bircher, S., Skou, N., and Kerr, Y. H.: Validation of SMOS L1C and L2 Products and Important Parameters of the Retrieval Algorithm in the Skjern River Catchment, Western Denmark, IEEE T. Geosci. Remote, 51, 2969-2985, doi:10.1109/TGRS.2012.2215041, 2013.

Björnsson, H. and Venegas, S. A.: A Manual for EOF and SVD Analyses of Climate Data, Report No. 97-1, Department of Atmospheric and Oceanic Sciences and Centre for Climate and Global Change Research, McGill University, 52, 1997.

Boussetta, S., Balsamo, G., Beljaars, A., Kral, T., and Jarlan, L.: Impact of a satellite-derived leaf area index monthly climatology in a global numerical weather prediction model, Int. J. Remote Sens., 34, 3520-3542, doi:10.1080/01431161.2012.716543, 2013.

Daganzo-Eusebio, E., Oliva, R., Kerr, Y., Nieto, S., Richaume, P., and Mecklenburg, S.: SMOS radiometer in the 1400-1427-MHz passive band: Impact of the RFI environment and approach to its mitigation and cancellation, IEEE T. Geosci. Remote, 51, 49995007, 2013.

de Rosnay, P. and Polcher, J.: Modelling root water uptake in a complex land surface scheme coupled to a GCM, Hydrol. Earth Syst. Sci., 2, 239-255, doi:10.5194/hess-2-239-1998, 1998.

de Rosnay P., Drusch, M., Boone, A., Balsamo, G., Decharme, B., Harris, P., Kerr, Y., Pellarin, T., Polcher, J., and Wigneron, J. P.: AMMA Land Surface Model Intercomparison Experiment coupled to the Community Microwave Emission Model: ALMIP-MEM, J. Geophys. Res., 114, D05108, doi:10.1029/2008JD010724, 2009.

Dee, D. P., Uppala, S. M., Simmons, A. J., Berrisford, P., Poli, P., Kobayashi, S., and Andrae, U.: The ERA-Interim Reanalysis: Configuration and Performance of the Data Assimilation System, Q. J. Roy. Meteor. Soc., 137, 553-597, doi:10.1002/qj.828, 2011.

Dente, L., Su, Z., and Wen, J.: Validation of SMOS Soil Moisture Products over the Maqu and Twente Regions, Sensors, 12, 99659986, doi:10.3390/s120809965, 2012.

d'Orgeval, T., Polcher, J., and de Rosnay, P.: Sensitivity of the West African hydrological cycle in ORCHIDEE to infiltration processes, Hydrol. Earth Syst. Sci., 12, 1387-1401, doi:10.5194/hess-12-1387-2008, 2008.

Drusch, M., Wood, E., and Jackson, T.: Vegetative and atmospheric corrections for soil moisture retrieval from passive microwave remote sensing data: Results from the Southern Great Plains Hydrology Experiment 1997, J. Hydrometeorol., 2, 181-192, 2001.
Entekhabi, D., Njoku, E. G., O’Neill, P. E., Kellogg, K. H., Crow, W. T., Edelstein, W. N., Entin, J. K., Goodman, S. D., Jackson, T. J., Johnson, J., Kimball, J., Piepmeier, J. R., Koster, R. D., Martin, N., McDonald, K. C., Moghaddam, M., Moran, S., Reichle, R., Shi, J. C., Spencer, M. W., Thurman, S. W., Tsang, L., and Van Zyl, J.: The Soil Moisture Active Passive (SMAP) Mission, P. IEEE, 98, 704-716, doi:10.1109/JPROC.2010.2043918, 2010.

Escorihuela, M. J., Chanzy, A., Wigneron, J. P., and Kerr, Y.: Effective Soil Moisture Sampling Depth of L-Band Radiometry: A Case Study, Remote Sens. Environ., 114, 995-1001, doi:10.1016/j.rse.2009.12.011, 2010.

Freitas, S. C., Trigo, I. F., and Dias, J. B.: Error propagation in the LSA-SAF algorithm for Land Surface Temperature, Proceedings of the 2007 EUMETSAT Meteorological Satellite Conference, Amsterdam, the Netherlands, 24-28 September 2007.

González-Zamora, A., Sánchez, N., Gumuzzio, A., Piles, M., Olmedo, E., and Martínez-Fernández, J.: Validation of SMOS L2 and L3 soil moisture products over the Duero Basin at different spatial scales. The International Archives of Photogrammetry, Remote Sensing and Spatial Information Sciences, XL7/W3, 2015.

Green, W. H. and Ampt, G.: Studies on soil physics, 1. the flow of air and water through soils, J. Agr. Sci., 4, 1-24, 1911.

Haylock, M. R., Hofstra, N., Klein Tank, A. M. G., Klok, E. J., Jones, P. D., and New, M.: A European daily high-resolution gridded dataset of surface temperature and precipitation, J. Geophys. Res.-Atmos., 113, D20119, doi:10.1029/2008JD010201, 2008.

Hofstra, N., New, M., and McSweeney, C.: The influence of interpolation and station network density on the distributions and trends of climate variables in gridded daily data, Clim. Dynam., 35, 841-858, doi:10.1007/s00382-009-0698-1, 2010.

Holmes, T. R. H., Jackson, T. J., Reichle, R. H., and Basara, J. B.: An assessment of surface soil temperature products from numerical weather prediction models using ground-based measurements, Water Resour. Res., 48 W02531, doi:10.1029/2011WR010538, 2012.

Hourdin, F.: Etude et simulation numérique de la circulation générale des atmosphères planétaires, $\mathrm{PhD}$ Thesis, available at: www.lmd.jussieu.fr/ hourdin/these.pdf (last access: 6 January 2017), 1992.

Jones, A., Vukićević, T., and Vonder Haar, T.: A microwave satellite observational operator for variational data assimilation of soil moisture, J. Hydrometeorol., 5, 213-229, 2004.

Kanamitsu, M., Yoshimura, K., Yhang, Y.-B., and Hong, S.Y.: Errors of Interannual Variability and Trend in Dynamical Downscaling of Reanalysis, J. Geophys. Res., 115, 17115, doi:10.1029/2009JD013511, 2010.

Kerr, Y., Waldteufel, P., Wigneron, J. P., Delwart, S., Cabot, F., Boutin, J., Escorihuela, M., Font, J., Reul, N., Gruhier, C., Juglea, S., Drinkwater, M., Hahne, A., Martin-Neira, M., and Mecklenburg, S.: The SMOS mission: New tool for monitoring key elements of the global water cycle, P. IEEE, 98, 666-687, 2010.

Kerr, Y., Waldteufel, P., Richaume, P., Wigneron, J. P., Ferrazzoli, P., Mahmoodi, A., Bitar, A. A., Cabot, F., Gruhier, C., Juglea, S., Leroux, D., Mialon, A., and Delwart, S.: The SMOS soil moisture retrieval algorithm, IEEE T. Geosci. Remote, 50, 13841403, 2012. 
Kolassa, J., Aires, F., Polcher, J., Pringent, C., Jiménez, C., and Pereira, J. M.: Soil moisture retrieval from multiinstrument observations: Information content analysis and retrieval methodology, J. Geophys. Res.-Atmos., 118, 4847-4859, doi:10.1029/2012JD018150, 2013.

Krinner, G., N. Viovy, N., de Noblet-Ducoudré, N., Ogée, J., Polcher, J., Friedlingstein, P., Ciais, P., Stich, S., and Prentice, I. C.: A Dynamic Global Vegetation Model for Studies of the Coupled Atmosphere-Biosphere System, Global Biogeochem. Cy., 19, GB1015, doi:10.1029/2003GB002199, 2005.

Le Vine, D., Lagerloef, G. S. E., and Torrusio, S.: Aquarius and remote sensing of sea surface salinity from space, P. IEEE, 98, 688-703, doi:10.1109/JPROC.2010.2040550, 2010.

Marthews, T. R., Quesada, C. A., Galbraith, D. R., Malhi, Y., Mullins, C. E., Hodnett, M. G., and Dharssi, I.: High-resolution hydraulic parameter maps for surface soils in tropical South America, Geosci. Model Dev., 7, 711-723, doi:10.5194/gmd-7711-2014, 2014.

Mätzler, C. and Standley, A.: Technical Note: Relief Effects for Passive Microwave Remote Sensing, Int. J. Remote Sens., 21, 2403 2412, doi:10.1080/01431160050030538, 2000.

McMullan K., Brown, M., Martín-Neira, M., Rits, W., Ekholm, S., Marti, J., and Lemanczyck, J.: "SMOS: The payload", IEEE T. Geosci. Remote, 46, 594-605, 2008.

Milly, P. C. D.: Potential evaporation and soil moisture in general circulation models, J. Climate, 5, 209-226, 1992.

Montzka, C., Bogena, H., Weihermüller, L., Jonard, F., Dimitrov, M., Bouzinac, C., Kainulainen, J., Balling, J. E., Vanderborght, J., and Vereecken, H.: Radiobrightness validation on different spatial scales during the SMOS validation campaign 2010 in the Rur catchment, Germany, IEEE T. Geosci. Remote, 51, 17281743, doi:10.1109/TGRS.2012.2206031, 2013.

Ngo-Duc, T., Polcher, J., and Laval, K.: A 53-Year Forcing Data Set for Land Surface Models, J. Geophys. Res., 110, 2156-2202, doi:10.1029/2004JD005434, 2005.

Oliva, R., Martín-Neira, M., Corbella, I., Torres, F., Kainulainen, J., Tenerelli, J., Cabot, F., and Martin-Porqueras, F.: SMOS calibration and instrument performance after one year in orbit, IEEE T. Geosci. Remote, 51, 654-670, 2013.

Parrens, M., Zakharova, E., Lafont, S., Calvet, J.-C., Kerr, Y., Wagner, W., and Wigneron, J.-P.: Comparing soil moisture retrievals from SMOS and ASCAT over France, Hydrol. Earth Syst. Sci., 16, 423-440, doi:10.5194/hess-16-423-2012, 2012.

Pellarin, T., Wigneron, J. P., Calvet, J.-C., and Waldteufel, P.: Global soil moisture retrieval from a synthetic L-band brightness temperature data set, J. Geophys. Res.-Atmos., 108, 4364, doi:10.1029/2002JD003086, 2003.

Polcher, J., Piles, M., Gelati, E., Tello, M., and Barella-Ortiz, A.: Comparing Upper-Soil moisture from SMOS and a land-surface model over the Iberian Peninsula, Remote Sens. Environ., 174, 69-81, doi:10.1016/j.rse.2015.12.004, 2016.

Post, W. M. and Zobler, L.: Global Soil Types, 0.5-Degree Grid (Modified Zobler), Oak Ridge National Laboratory Distributed Active Archive Center, Oak Ridge, Tennessee, USA, available at: http://www.daac.ornl.gov (last access: 6 January 2017), 2000.
Rüdiger, C., Walker, J. P., Kerr, Y. H., Mialon, A., Merlin, O., and Kim, E. J.: Validation of the level 1c and level 2 SMOS products with airborne and ground-based observations, Proc. Int. Congr. MODSIM, Perth, Australia, 12-16 December 2011.

Sánchez, N., Martínez-Fernández, J., Scaini, A., and PérezGutiérrez, C.: Validation of the SMOS L2 Soil Moisture Data in the REMEDHUS Network (Spain), IEEE T. Geosci. Remote, 50, 1602-1611, doi:10.1109/TGRS.2012.2186971, 2012.

Santaren, D., Peylin, P., Viovy, N., and Ciais, P.: Optimizing a process-based ecosystem model with eddy-covariance flux measurements: a pine forest in southern France, Global Biogeochem. Cy., 21, GB2013, doi:10.1029/2006GB002834, 2007.

Schlenz, F., dall'Amico, J. T., Mauser, W., and Loew, A.: Analysis of SMOS brightness temperature and vegetation optical depth data with coupled land surface and radiative transfer models in Southern Germany, Hydrol. Earth Syst. Sci., 16, 3517-3533, doi:10.5194/hess-16-3517-2012, 2012.

Schulz, J. P., Dümenil, L., and Polcher, J.: On the Land SurfaceAtmosphere Coupling and Its Impact in a Single-Column Atmospheric Model, J. Appl. Meteorol., 40, 642-663, 2001.

Ulaby, F. T., Moore, R. K., and Fung, A. K.: Microwave Remote Sensing (Active and Passive), vol. 2, Addison-Wesley, Reading, MA, 1986.

Viterbo, P. and Beljaars, A.: An improved land surface parameterization scheme in the ECMWF model and its validation, J. Climate, 8, 2716-2748, 1995.

Wang, F., Cheruy, F., and Dufresne, J.-L.: The improvement of soil thermodynamics and its effects on land surface meteorology in the IPSL climate model, Geosci. Model Dev., 9, 363-381, doi:10.5194/gmd-9-363-2016, 2016.

Wang, J. R. and Schmugge, T.: An empirical model for the complex dielectric permitivity of soils as a function of water content, IEEE T. Geosci. Remote, 18, 288-295, 1980.

Wigneron, J. P., Laguerre, L., and Kerr, H.: A Simple Parameterization of the L-band Microwave Emission from Rough Agricultural Soils, IEEE T. Geosci. Remote, 39, 1697-1707, 2001.

Wigneron, J. P., Kerr, Y., Waldteufel, P., Saleh, K., Escorihuela, M., Richaume, P., Ferrazzoli, P., Grant, J. P., Hornbuckle, B., de Rosnay, P., Calvet, J.-C., Pellarin, T., Gurney, R., and Mätzler, C.: L-band microwave emission of the biosphere (L-MEB) model: Results from calibration against experimental data sets over crop fields, Remote Sens. Environ., 107, 4, 639-655, 2007.

Wilheit, T. T.: Radiative transfert in plane stratified dielectric, IEEE T. Geosci. Remote, 16, 138-143, 1978.

World Water Assessment Programme (WWAP): The United Nations World Water Development Report 4: Managing Water under Uncertainty and Risk, Paris, UNESCO, 2012.

Zollina, O., Kapala, A., Simmer, C., and Gulev, S. K.: Analysis of extreme precipitation over Europe from different reanalyses: a comparative assessment, Global Planet. Change, 44, 129-161, 2004. 